فيصل عيسى عبد القادر النواصره موسى سليمان صالح أبو زيتون

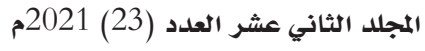

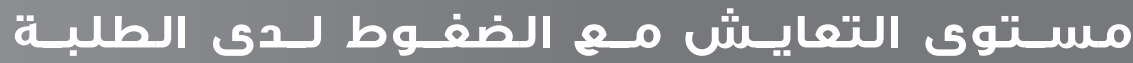

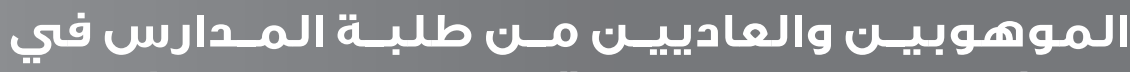

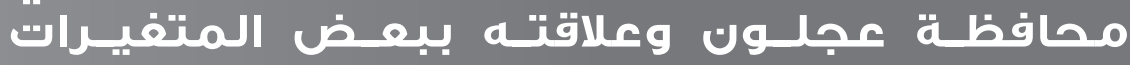

\section{وبالتصصيل الدراسي وصي}

الاستــلام : 21 / 2021 / إبريل/2021

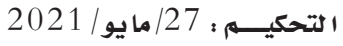

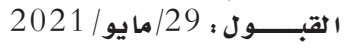

\section{فيصل عيسى عبد القادر النواصره(1،*) موسى سليمان صالح أبو زيتون}

(C) 2021 University of Science and Technology, Yemen. This article can be distributed under the terms of the Creative Commons Attribution License, which permits unrestricted use, distribution, and reproduction in any medium, provided the original author and source are credited.

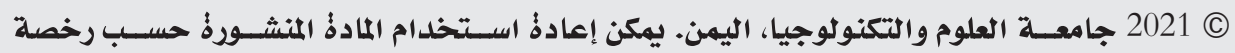
مؤسسة المشاع الإبداعي شريطة الاستشهاد بالمؤلف والمجلة. 
مستوى التعايش مع الضغوط لدى الطلبة الموهوبين والعاديين من طلبة

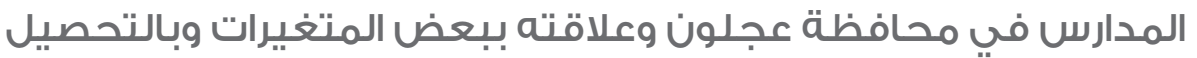
الدراسي

الملخص:

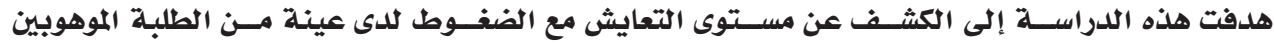

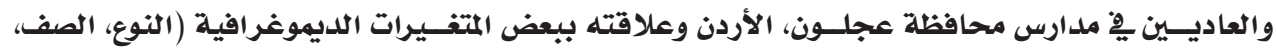

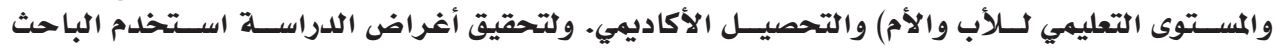

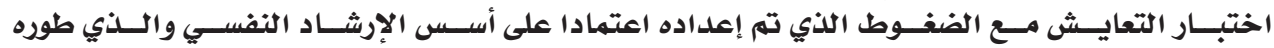

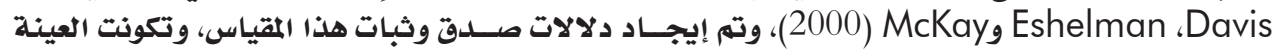

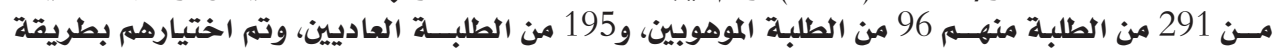

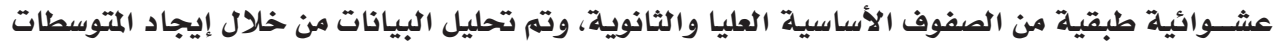

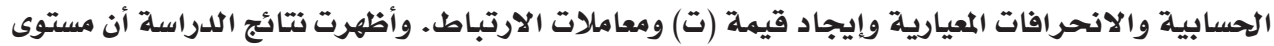

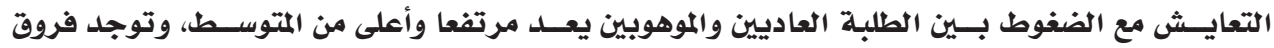

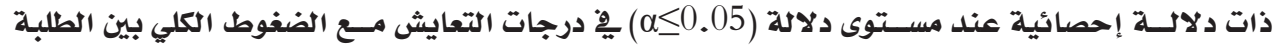

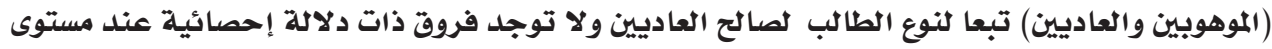

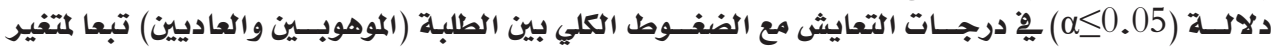

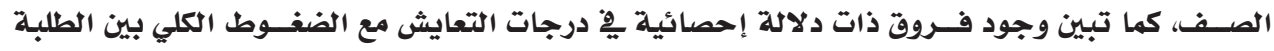

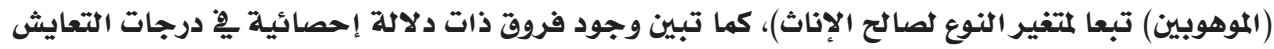

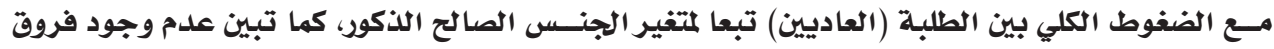

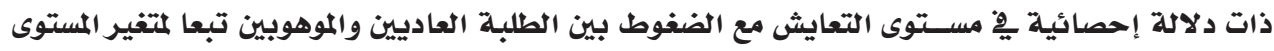

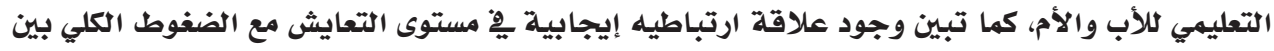

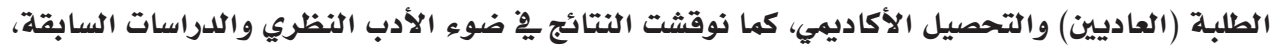
وتم اقتراح بعض التوصيات بناء على نتائج الدراسية. الكلمات المفتاحية : التعايث مع الضفوط، الموهوبين، التحصيل الدراسي، المتفيرات الديمغرافية. 
فيصل عيسى عبد القادر النواصره موسى سليمان صالح أبو زيتون

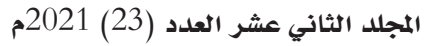

\title{
The Level of Coexistence with Pressures Among Talented and Average Students at Ajloun Area in Relation to Some Demographic Variables and Academic Achievement
}

\begin{abstract}
:
The study aimed to identify the level of coexistence with pressures among a sample of talented and average students at schools in Ajloun area, Jordan in relation to some demographic variables, such as gender, class, educational level of parents, and academic achievement. To achieve this, the coexistence with pressures test, which was prepared according to psychological counseling and developed by Davis, Eshelman, and McKay (2000), was used. The validity and reliability of the test was tested. The sample consisted of 291 (96 talented students and 195 average students), who were selected by the random stratified method from high basic and secondary schools. The data was analyzed by using the arithmetic means, standard deviation, T. Test, ANOVA and the correlation coefficients. The results showed that the level of coexistence with pressures between the talented and average students was high and more than the medium, and there were statistically significant differences $(\alpha \leq 0.05)$ in the total degree of coexistence with pressures between talented and average students attributed to students type in favor of the average students. There were not any statistically significant differences in the total degree of coexistence with pressures between talented and average students attributed to the class variable. However, there were statistically significant differences $(\alpha \leq 0.05)$ in the total degree of coexistence with pressures among talented students attributed to the gender variable in favor of females, and there were statistically significant differences $(\alpha \leq 0.05)$ in the total degree of coexistence with pressures among average students attributed to gender variable in favor of males. Also, there were not any statistically significant differences in the total degree of coexistence with pressures between talented and average students attributed to parents' education variable. There was a positive correlation coefficient in the level of coexistence with pressures degrees between the average students and the academic achievement. The results were discussed in the light of the theoretical framework and previous studies. In view of the findings, the study concluded with some recommendations.
\end{abstract}

Keywords: coexistence with pressures, talented, academic achievement, demographic variables. 


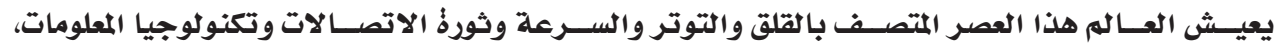

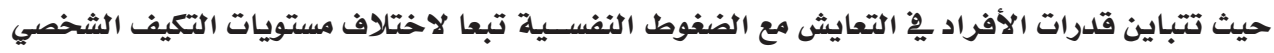

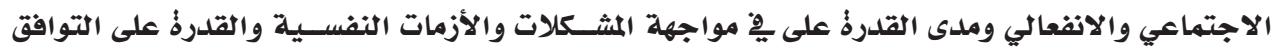

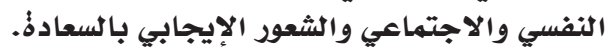

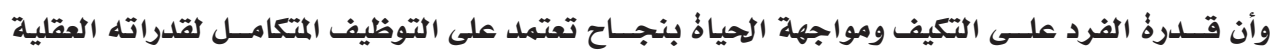

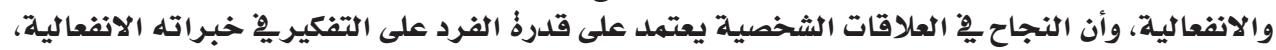
واستجابته وفقا لذلك (عباس، 2010).

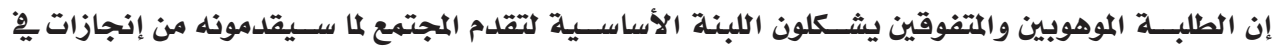

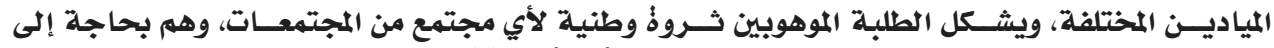
تطوير قدراتهم ومجالات تميزهم ورعايتها (Mendaglio, 2005).

يطور الأطفال الموهوبون والمتفوقون قدراتهم العقلية والمعرفية بهعدل أسـرع بكثير من معدلاتهم النهمائية

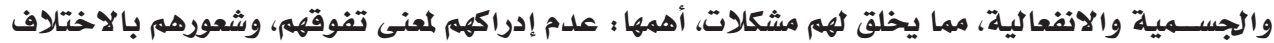

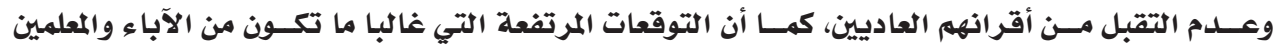

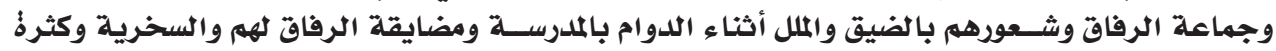

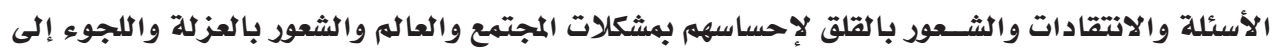

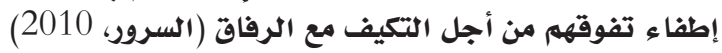

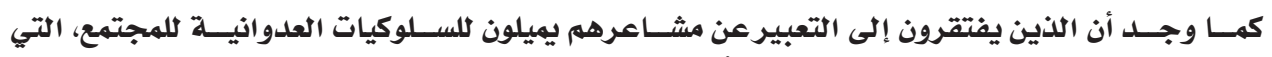

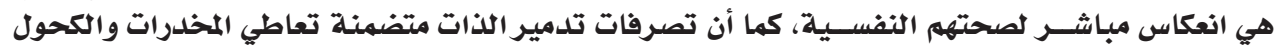

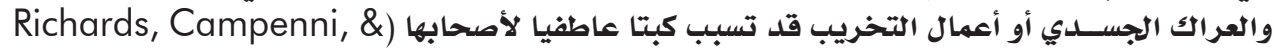
.(Muse-Burke, 2010

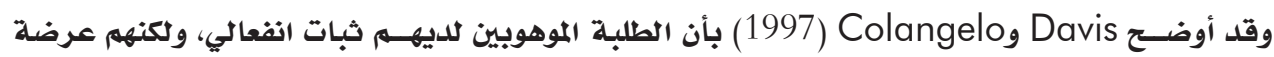

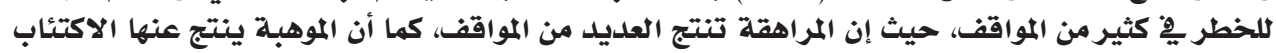

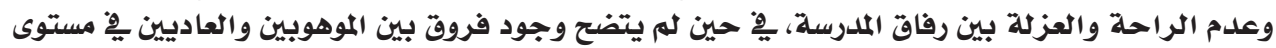
الاكتئاب.

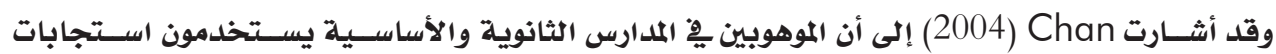

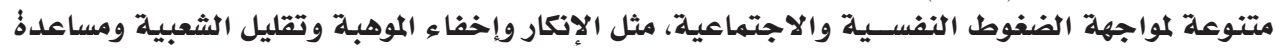

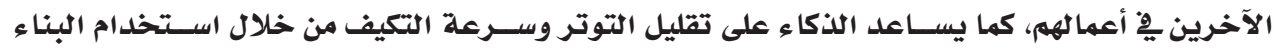

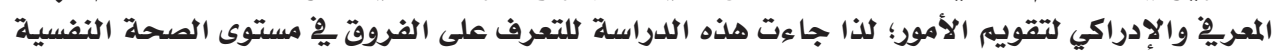

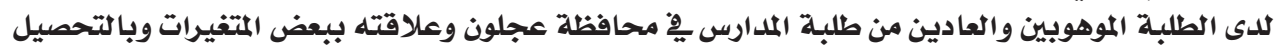
الدراسي.

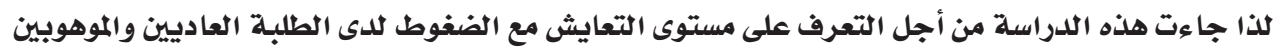

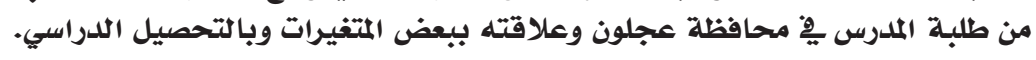

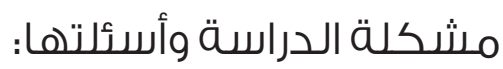

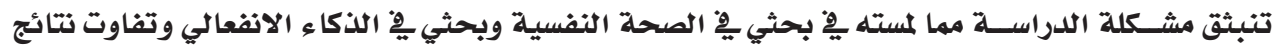

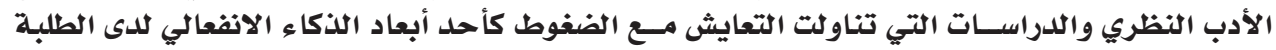

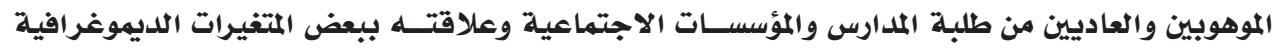


فيصل عيسى عبد القادر النواصره موسى سليمان صالح أبو زيتون

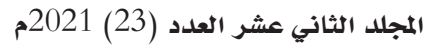

وبالتحصيل الدراسي وخاصة دراسة السليمان (2011) ودراسة الحوامدةٌ وبنات (2012) ودراسة العبدالة الله

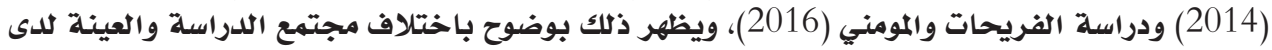

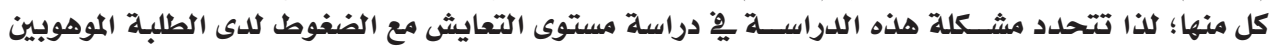

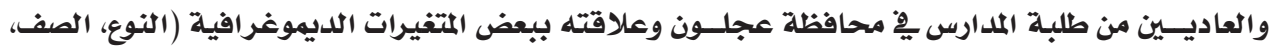
المستوى التعليمي للوالدين) والتحصيل مالدين الدراسي.

لذا حاولت هذه الدراسة الإجابة عن الأسئلة الآتية :

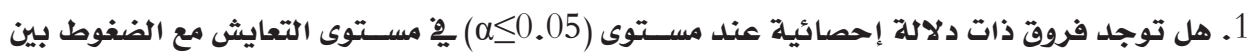

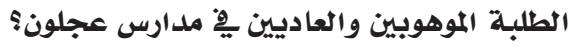

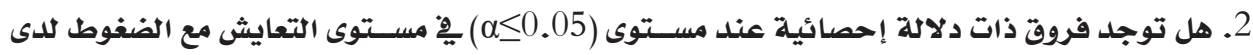

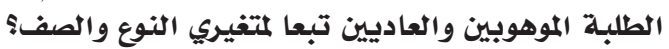

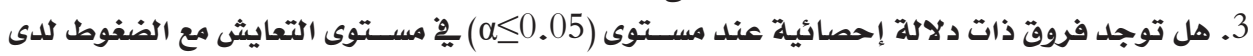

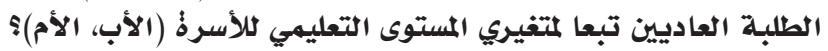

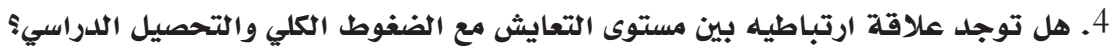

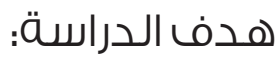

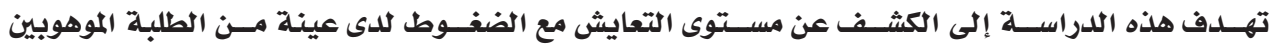

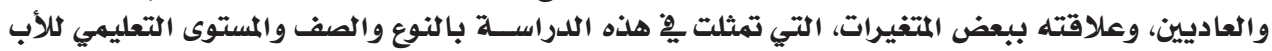
والأم والتحصيل الدراسي.

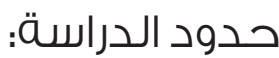

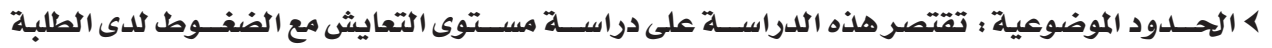

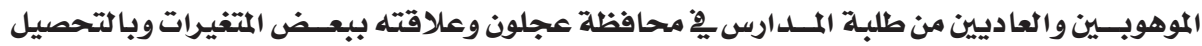

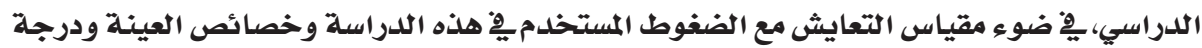

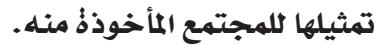

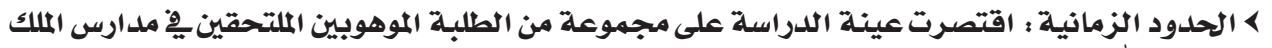

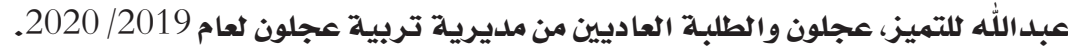

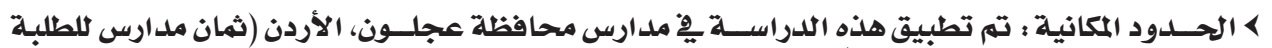

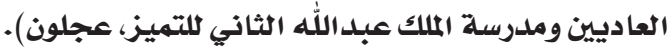
أهمية الدراسة:

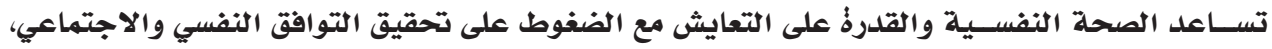

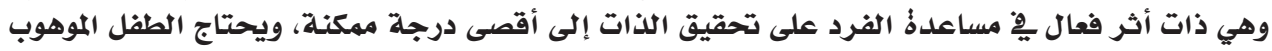

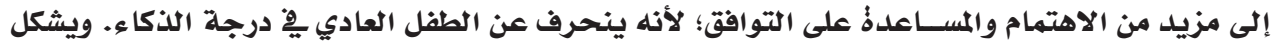

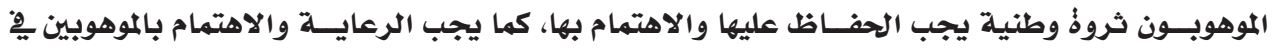

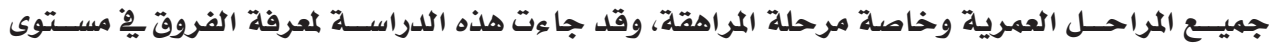

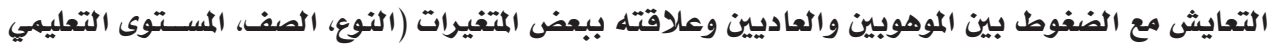

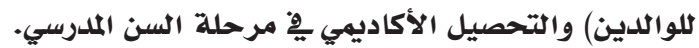

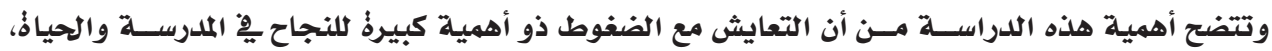

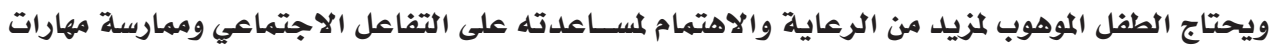

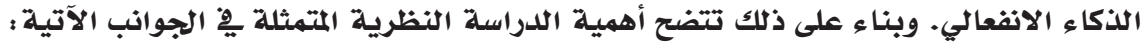

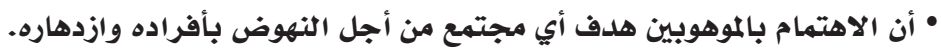


• يعد الوقوف على مستوى التعايش مع الضغوط للطلبة (الموهوبين والعاديين) جزء ألما من العملية التربوية

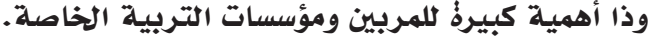

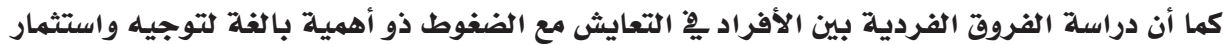

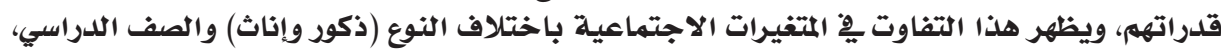

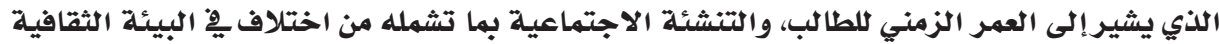

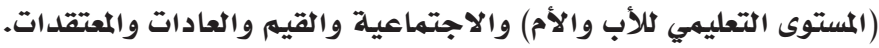

وتبلدو أهمية دراســة الفروق ِِّ مســتوى التعايش مع الضغوط بين الطلبـة الموهوبين والطلبـة العادين

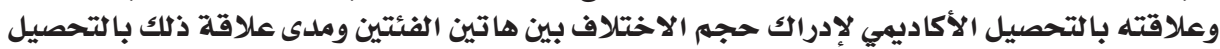

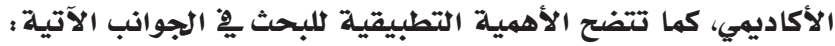

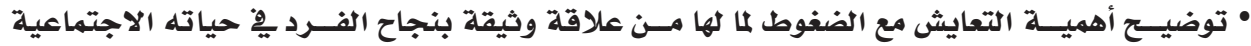
ومستقبله المهني.

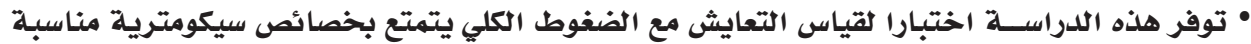
للبيئة الأردنية والعربية بشكل عام.

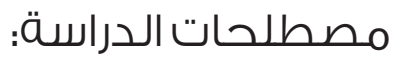

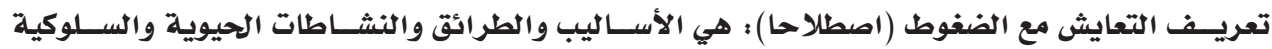

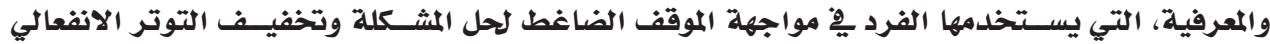
المترتب عليه (Seaward, 1999, 163).

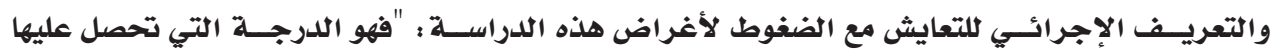

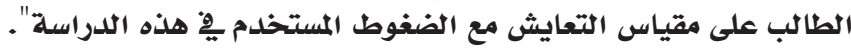

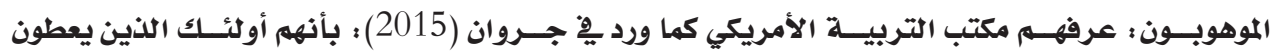

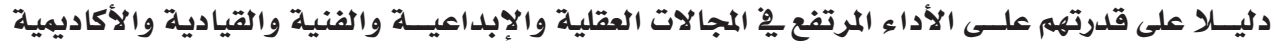

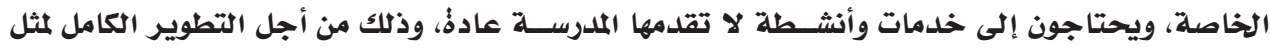

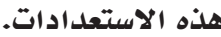

والتعريف الإجرائي للطفل الموهوب : هو الطفل الذي تم تشخيصه على أنه موهوب من قبل وزارذٌ التربية

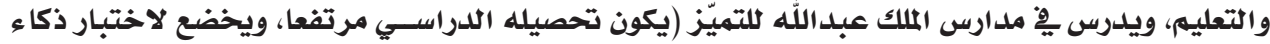
جمعي)

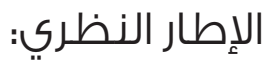

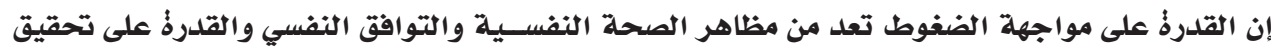

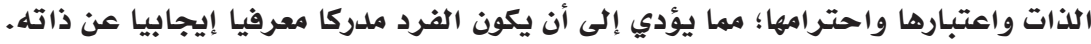

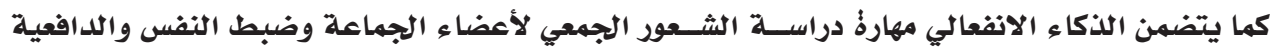

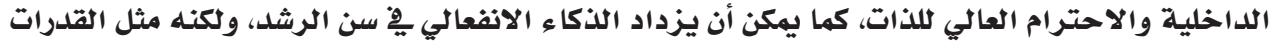

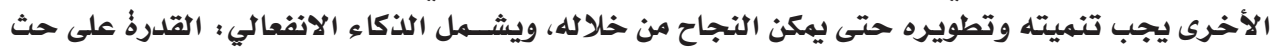

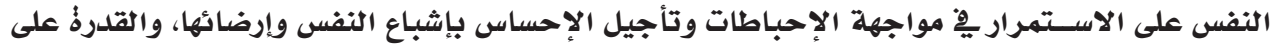

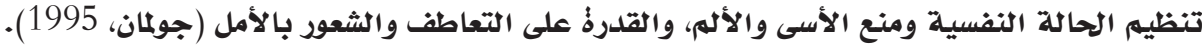


فيصل عيسى عبد القادر النواصره موسى سليمان صالح أبو زيتون

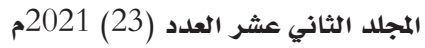

العوامل المسببـة للضغوط النفسية :

تُصنف العوامل المسببـة للضفوط النفسية إلى ثلاث فئات رئيسية هي (الظفيري، 2007)؛ 1. عوامل نفسية اجتماعية وتشمل أسلوب الحياءٌ ودرجة التكيف والتعب الزائد والإحباط والحرمان.

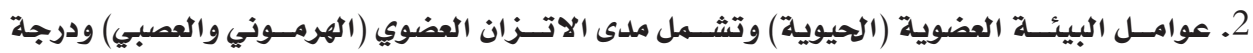

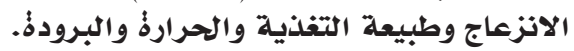

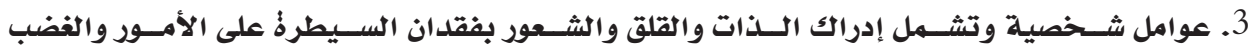
والعدوانية. أنواع الضغوط النفسية :

لقد صنف Moor الضغوط النفسية التي يواجهها الفرد يِ ثلاثة أنواع (الجبلي، 2006) :

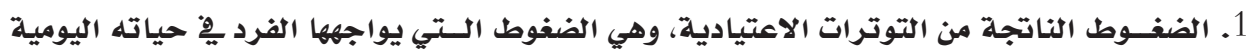

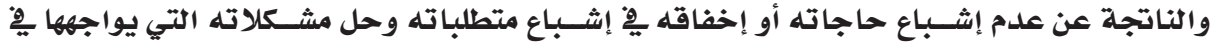
حياته اليومية. 2. الضغوط النمائية : وهي الضغوط الناتجة من التغيرات النمائية التي تتطلب تغيرا مؤقتا ِِِ العادات وبِّ أسلوب الحياذُ.

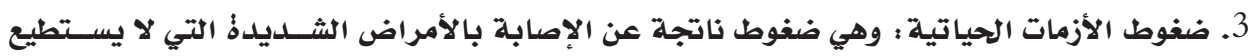
مقاومتها، أو فقدان عزيز وتستهمر لفترةٌ طويلة.

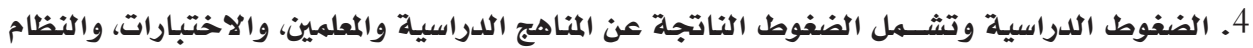

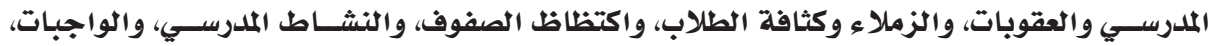

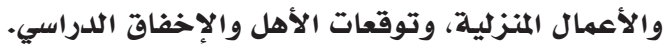
النظريات التي فسرت الضغوط :

هناك العديد من النظريات التي فسرت الضغوط منها (العبدالله، 2014؛ الجبلي، 2006؛ شتات، 2008)؛

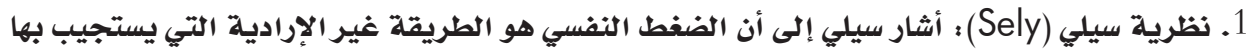

الجسل باستعداداته العقلية والبيئية لأي دافع وملى تعبير الفيره عن مشاعر التهديل والخوف.

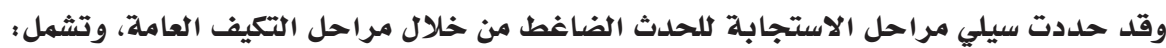

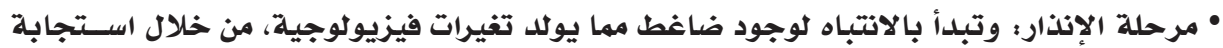

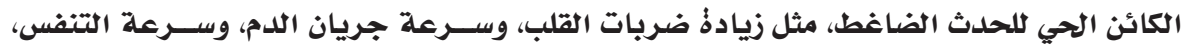

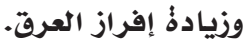

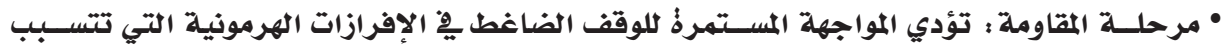

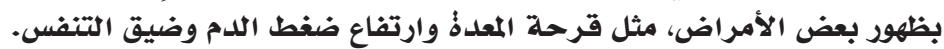

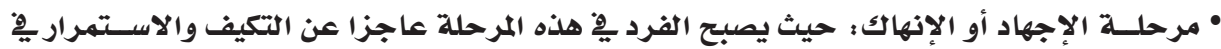

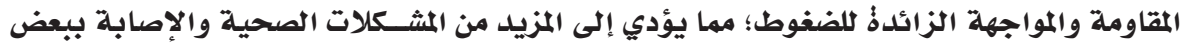

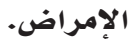

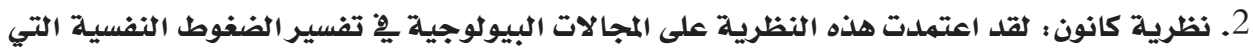

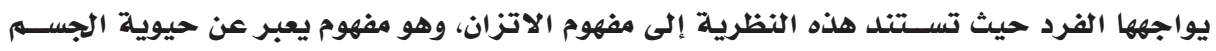

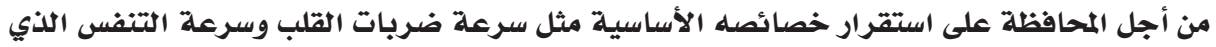

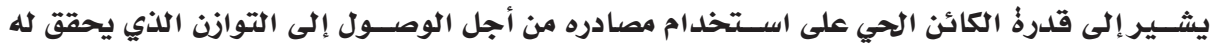
البقاء. 


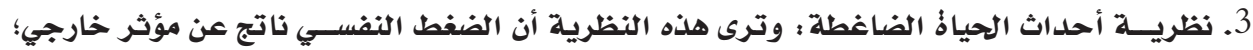

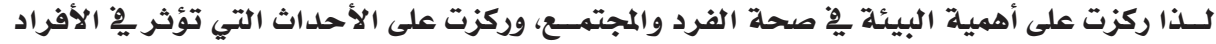

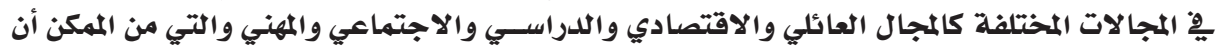
تكون إيجابية أو سلبية.

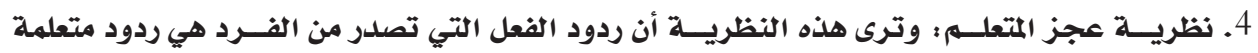

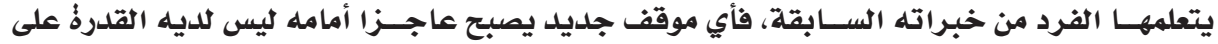

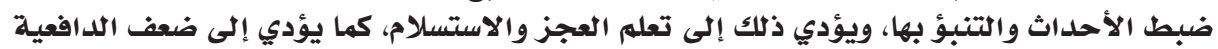

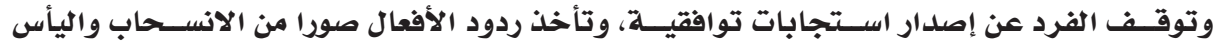

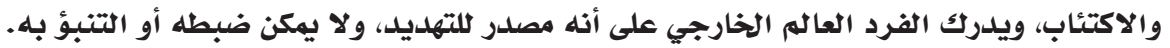

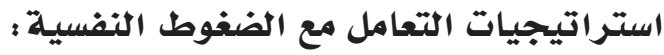

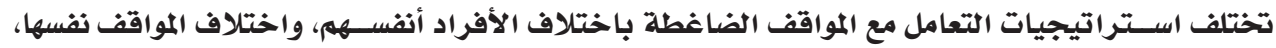

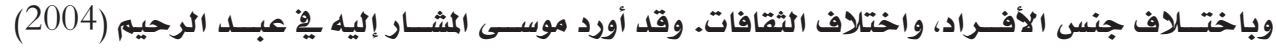

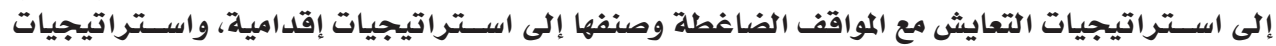

إحجامية.

1. الاســراتيجيات الإقدامية وهي التي تركز على الموقف الضاغط، حيث تعكس جهود الفرد المعرفية

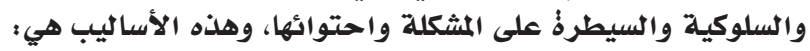

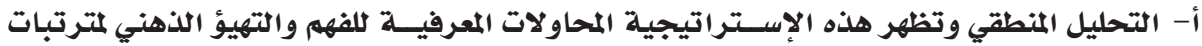
الموقف الضاغط.

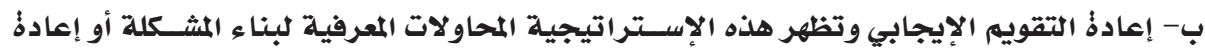

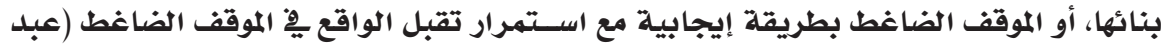
الرحيه، 2004).

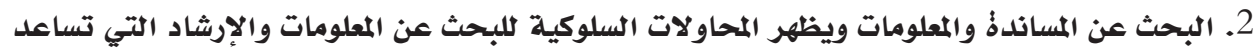

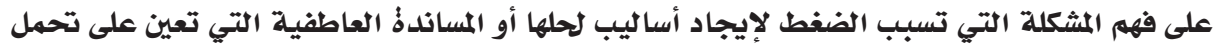

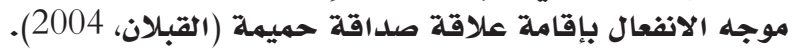

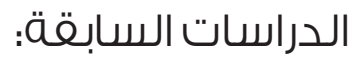

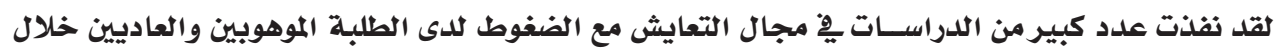

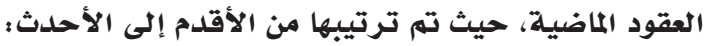

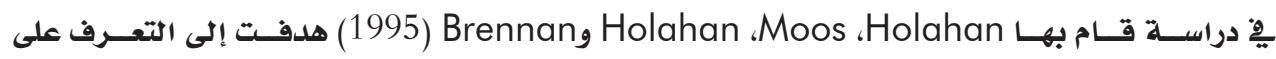

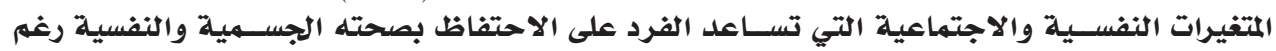

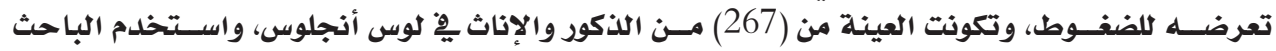

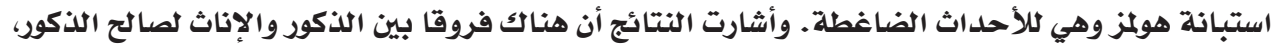

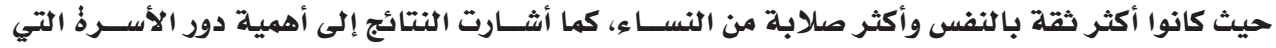

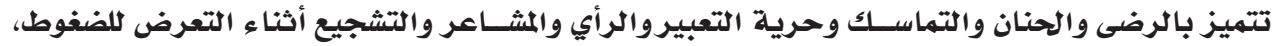

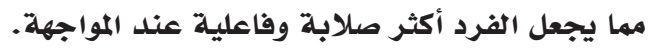

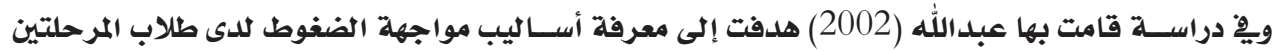

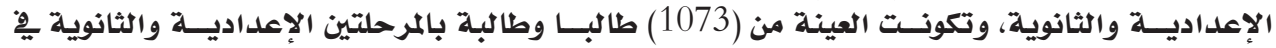

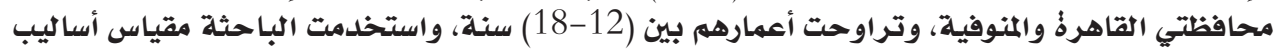

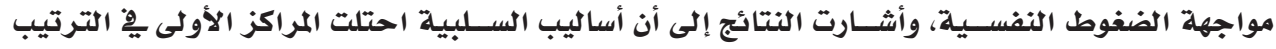

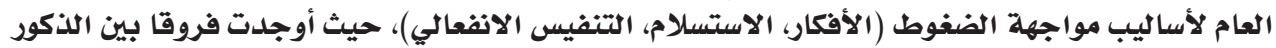
والإناث بشأن مواجهة الضغوط وفروق بين الإعدادية والثانوية على (15) أسلوب من أساليب المواجهة الإنها 
فيصل عيسى عبد القادر النواصره موسى سليمان صالح أبو زيتون

المجلد الثاني عشر العدد (23) 2021م سئون

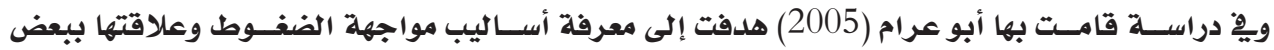

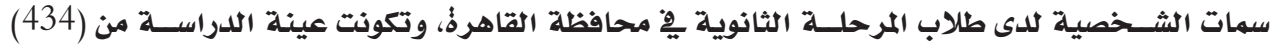

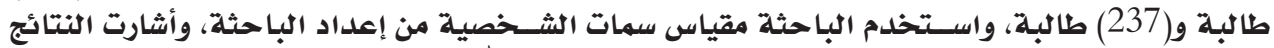

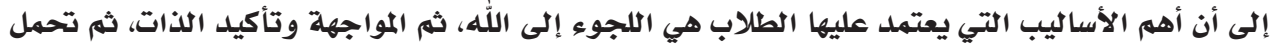

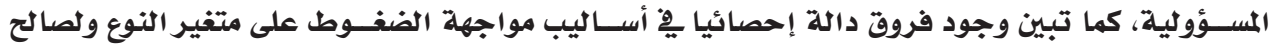

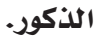

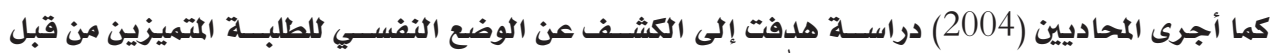

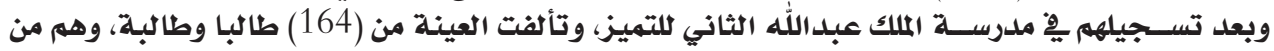

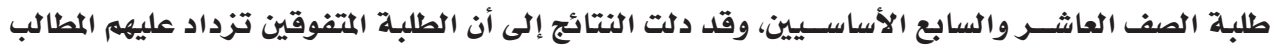

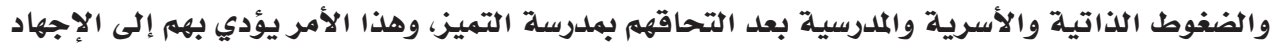

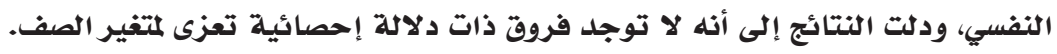

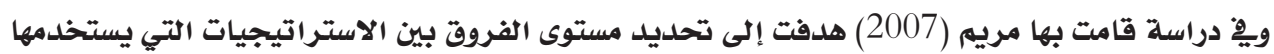

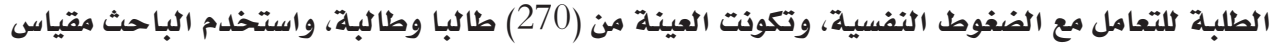

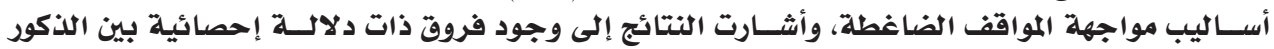

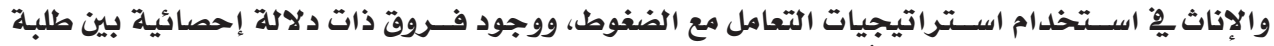

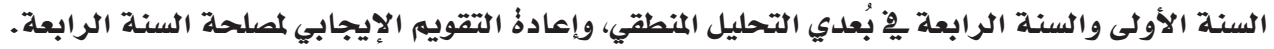
كما أجرى Barber-Marsh (2007) دراســة هدفت إلى التعرف على خبرات الطلبة الموهوبين المراهقين

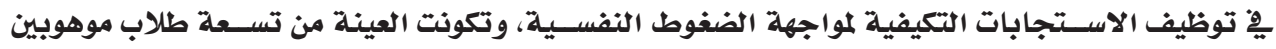

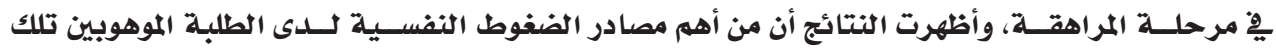

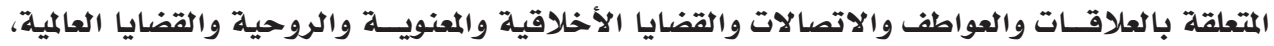

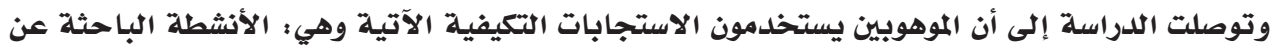

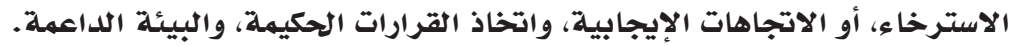

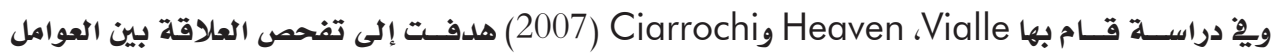

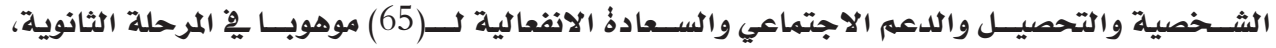

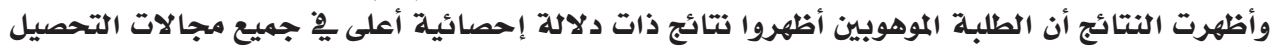

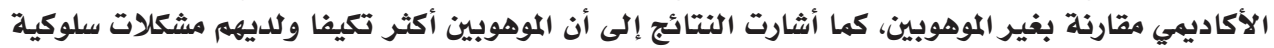
وانفعالية أقل من زملائهم غير الموهوبئ فوبين.

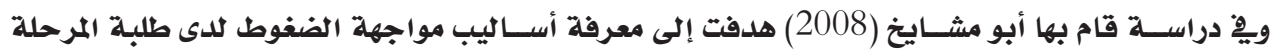

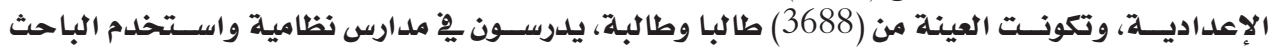

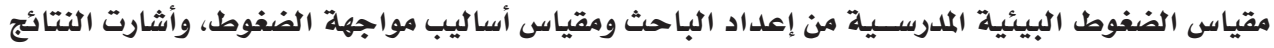

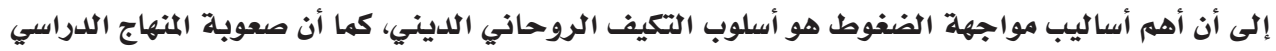

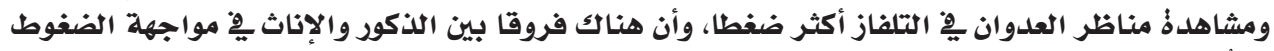

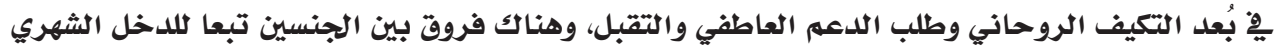
- مِّ مواجهة الضغوط.

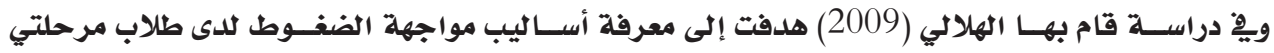

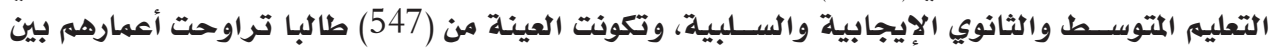

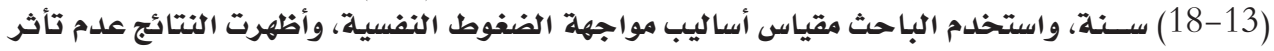

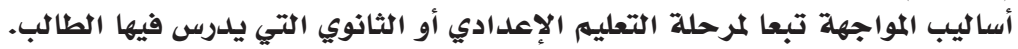




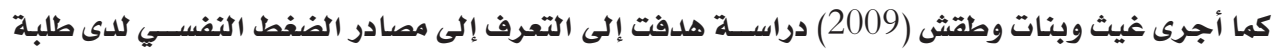

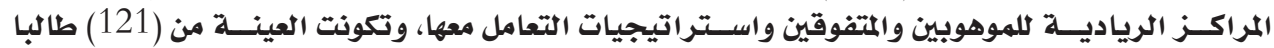

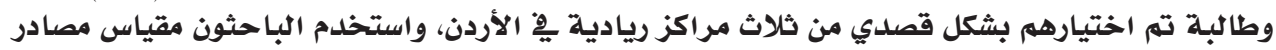

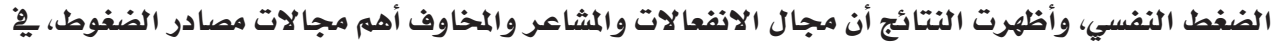

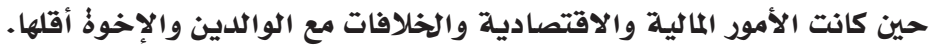

كما أجرى Swiatek و (2009) دراسة هلدفت إلى التعرف على الاستجابات التكيفية الاجتهاعية

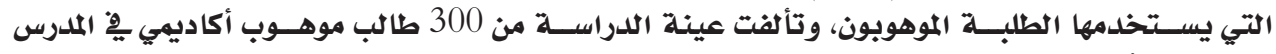

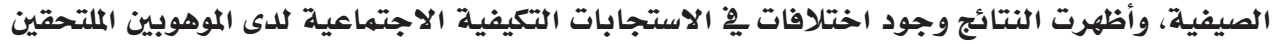

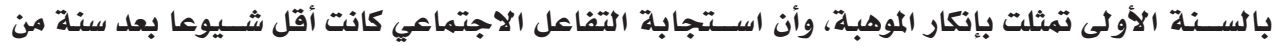

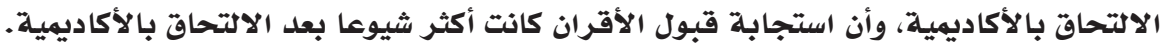

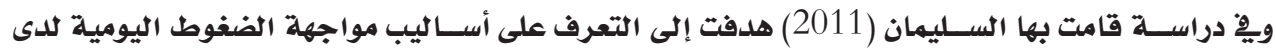

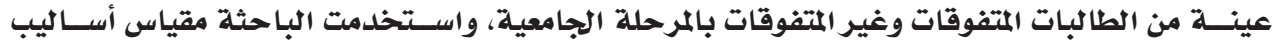

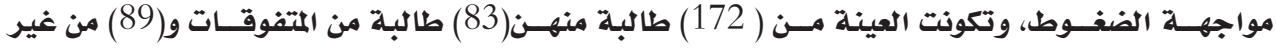

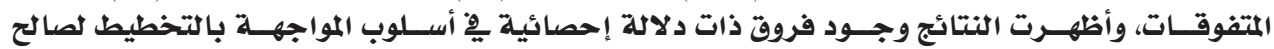

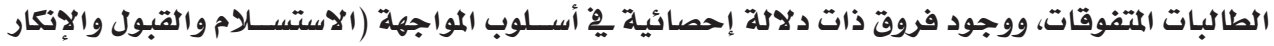

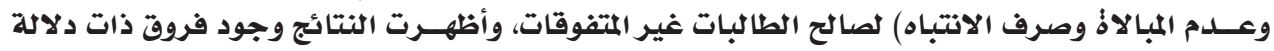

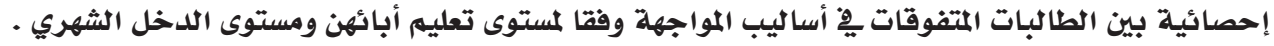

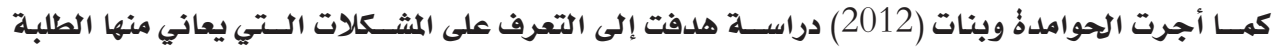

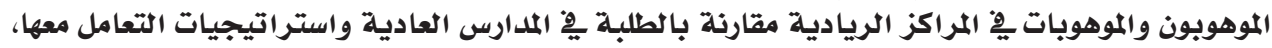

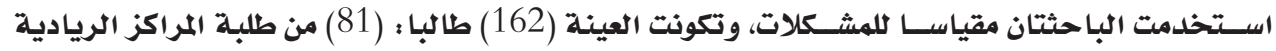

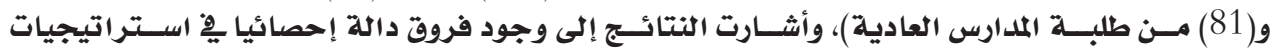

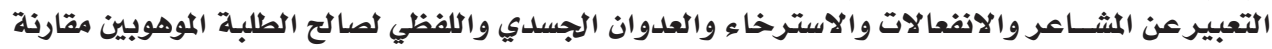

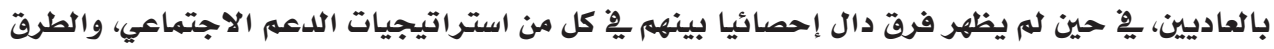

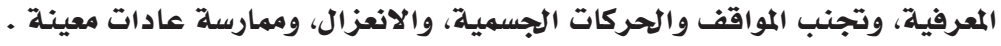

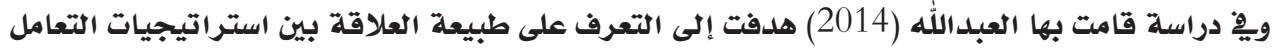

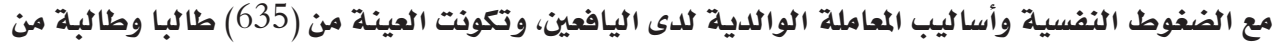

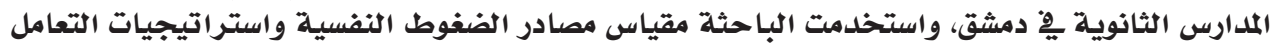

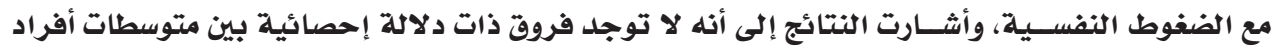

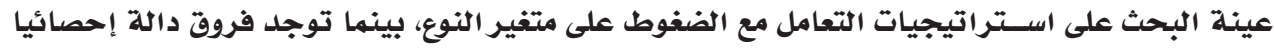

$$
\text { على متغير سنوات الدراسة. }
$$

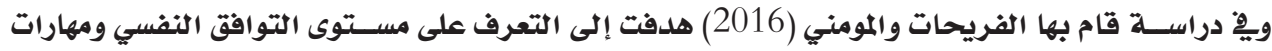

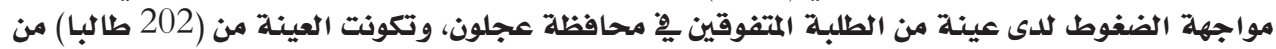

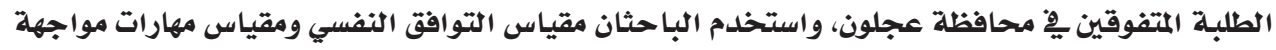

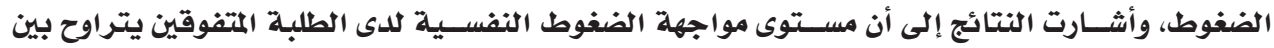

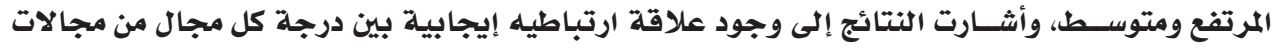

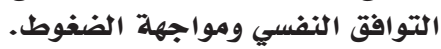

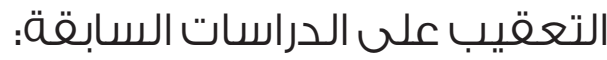

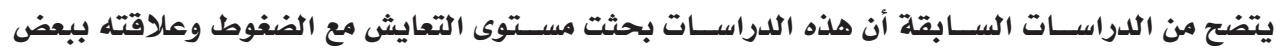

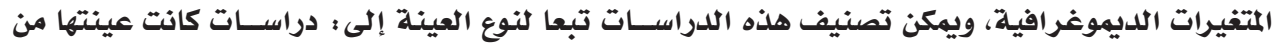


فيصل عيسى عبد القادر النواصره موسى سليمان صالح أبو زيتون

المجلد الثاني عشر العدد (23) 2021م سئون

طلبة المدارس مثل دراسة عبدالله (2002)، ودراسة أبو عرام (2005)، ودراسة المحاديين (2006)، ودراسة Barber-Marsh

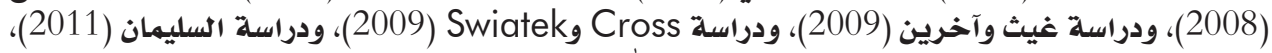

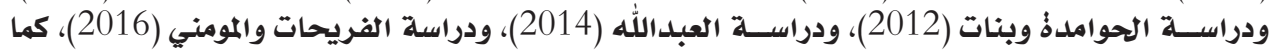

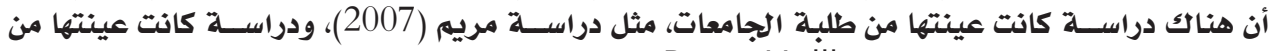

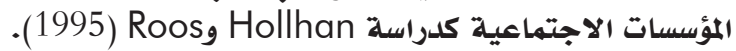

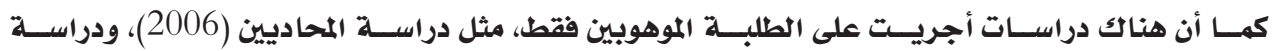
غيث وآخرين (2007) Barber-Marsh

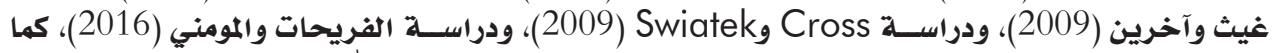

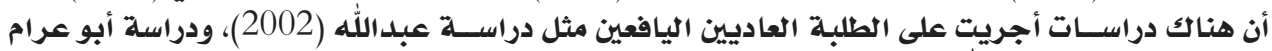

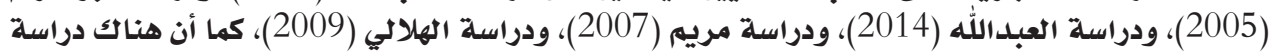
أجرت مقارنة بين الطلبة الموهوبين وغير الموهوبين، مثل دراسة السبة السليمان (2011)، ودراسلة (2011).

لذا جاءت الدراسة الحالية لبحث مستوى التعايش مع الضغوط للدى الطلبة الموهوبين والعاديين وعلاقيتها

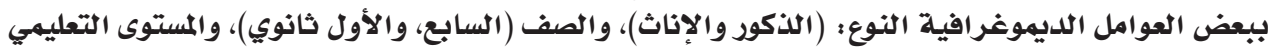

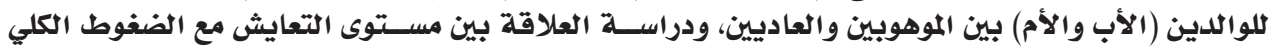

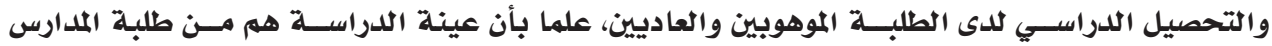

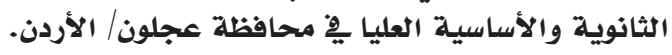

$$
\text { منهجية الدراسة وإجراءاتها: }
$$
مجتمع الدراسة وعينتها :

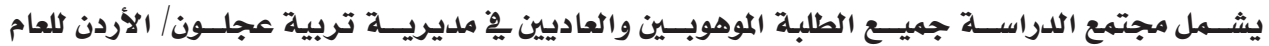

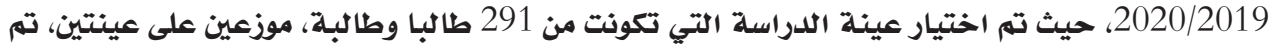

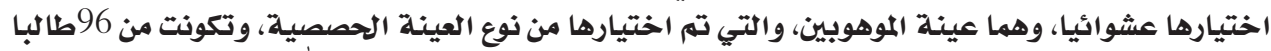

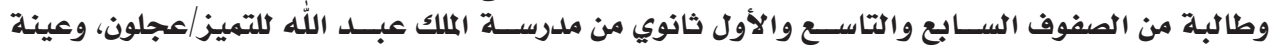

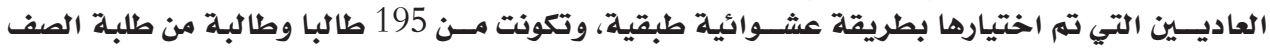

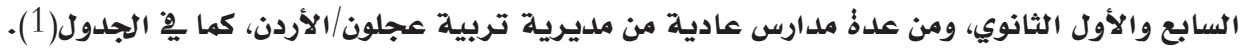
جلدول (1): أعداد الطلبة (أفراد العينة) حسب متغيرات الدراسة

\begin{tabular}{|c|c|c|c|}
\hline النسبة & التكرار & الفئات & المتغير \\
\hline 67.0 & 195 & عادي & نوع الطالب \\
\hline 33.0 & 96 & موهوب & \\
\hline 51.5 & 150 & ذكر & النوع ل \\
\hline 48.5 & 141 & أنثى & \\
\hline 59.5 & 173 & السابع & الصف الدراسي \\
\hline 40.5 & 118 & الأول الثانوي & \\
\hline 59.5 & 173 & ثانوية عامه فما دون & المستوى التعليمي للأب \\
\hline 40.5 & 118 & جامعي & \\
\hline 44.0 & 128 & ثانوية عامه فهما دون & المستوى التعليمي للام \\
\hline 56.0 & 163 & جامعي & \\
\hline 100.0 & 291 & & \\
\hline
\end{tabular}




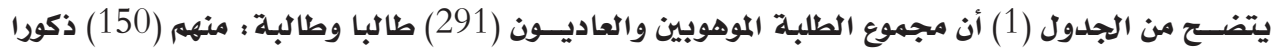

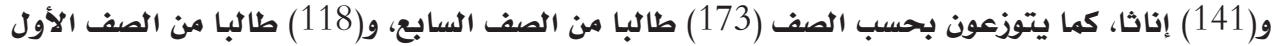

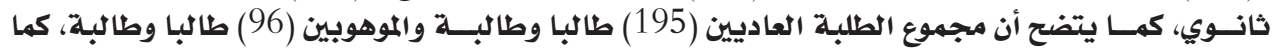

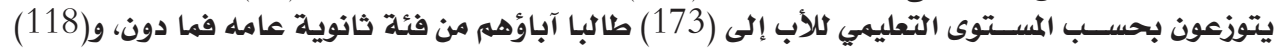

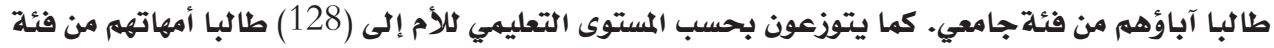

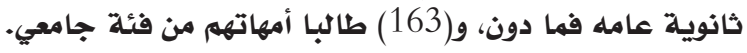

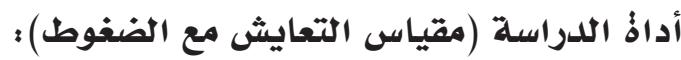

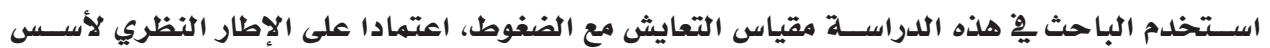

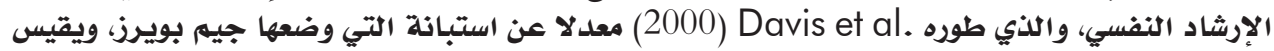

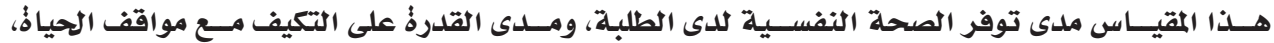

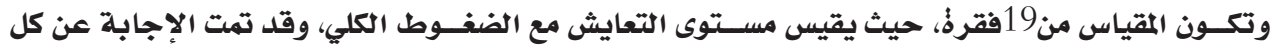

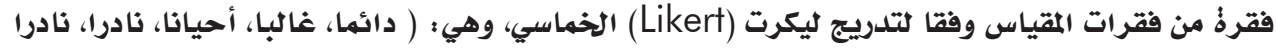

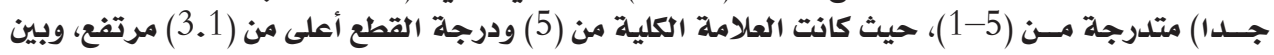

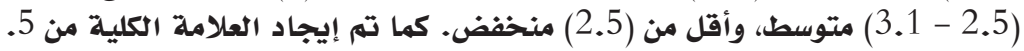

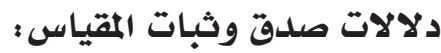

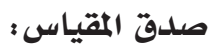

قام الباحثان بالتحقق من صلدق المقياس من خلال :

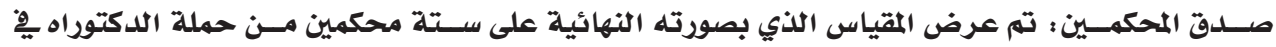

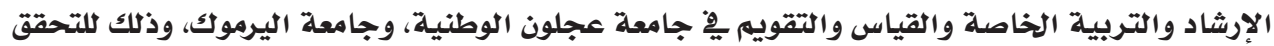

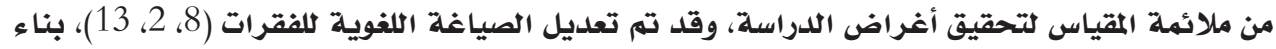

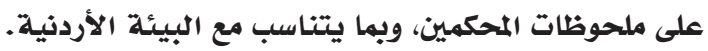

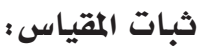

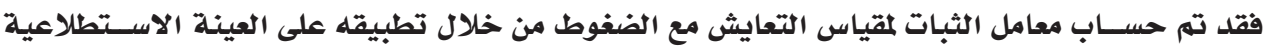

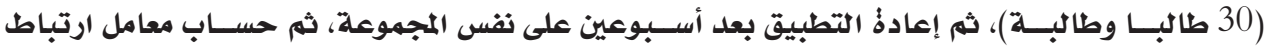

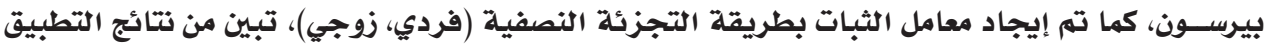

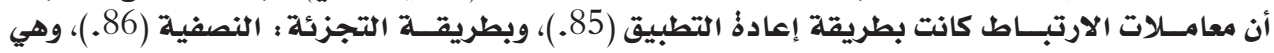

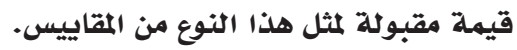
متغيرات الدراسة : تضمنت الدراسة المتفيرات الآتية :

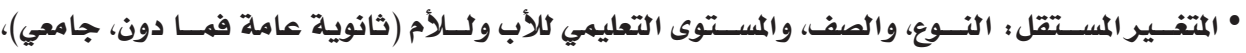
والتحصيل الدراسي. • المتفير التابع : مستوى التعايش التراسئ مع الضغوط.

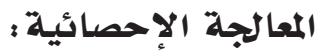

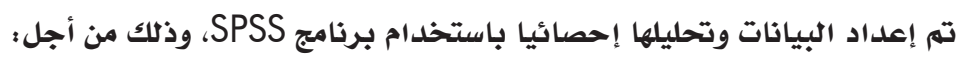

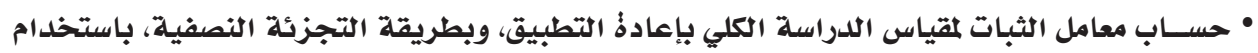
معامل ارتباط بيرسون. • حساب المتوسطات الحسابية والانحرافات المعيارية؛؛ لدرجات الأداء على مقياس التعايش مع الضغوط الكلي. 
فيصل عيسى عبد القادر النواصره موسى سليمان صالح أبو زيتون

المجلد الثاني عشر العدد (23) 2021م سئون

• اســتخلام (T.Test)؛ للتعرف على مســوى الدلالة الإحصائية للفروق بين المتوسطات الحسابية وفقا

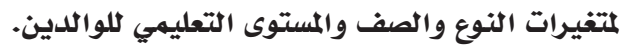

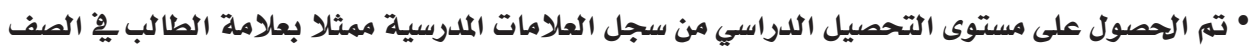

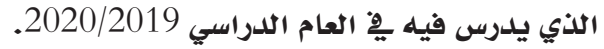

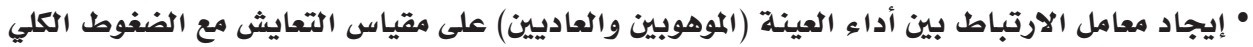

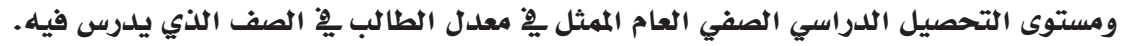

نتائج الدراسة ومناقة التحيتها:

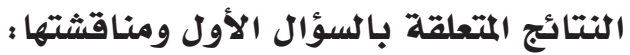

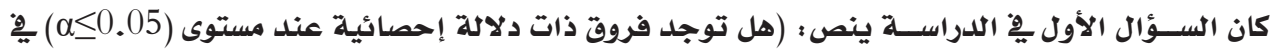

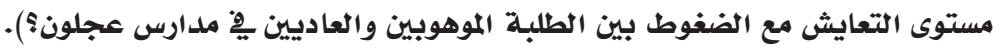

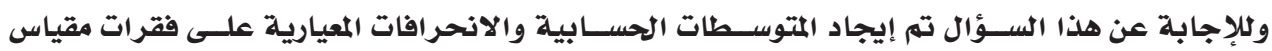

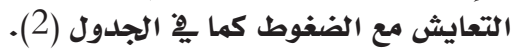

جلدول (2) : المتوسط الحسابي والانحراف المعياري على فقرات مقياس التعايث مع الضغوط على العينة الكلية

\begin{tabular}{|c|c|c|c|}
\hline الانحمراف & المتتوسطابي & الفقرات & الرقم \\
\hline 1.218 & 3.13 & أتجاهل احتياجاتي الخاصة وأركز ِِّ العمل بمزيد من الجلدية والسرعة. & 1 \\
\hline 1.225 & 3.10 & أبحث عن أصدقاء لإجراء حوار أو للسعي وراء مؤازرتهم. & 2 \\
\hline 1.338 & 3.06 & أشترك يِّ نوع ما من أنواع النشاط البدني. & 3 \\
\hline 1.382 & 3.01 & أصبح عصبيا وتنعكس هذه العصبية على من هم حولي. & 4 \\
\hline 1.232 & 3.63 & أخذ فسحة من الوقت كي أسترخي وألتقط أنفاسي وابتعد عن ضغط. & 5 \\
\hline 1.302 & 3.22 & أواجه مصادر الضغوط وأعمل على تغييرها. & 6 \\
\hline 1.281 & 3.07 & أنسحب عاطفيا وأنخرط يِّ البرنامج اليومي. & 7 \\
\hline 1.187 & 3.49 & أغير نظرتي للمشكلة وأنظر إليها من منظور أفضل. & 8 \\
\hline 1.398 & 3.00 & أُكثر من ساعات نومي عما أنا ِِِ حاجة إليه فعلا. & 9 \\
\hline 1.385 & 3.69 & آخذ بعض الراحة أثناء الدراسة. & 10 \\
\hline 1.285 & 3.42 & أخرج للتسوق وابتاع شيئا ما حتى أدخل السرور على نفسي. & 11 \\
\hline 1.216 & 3.98 & أمزح مع أصدقائي وأستعين بالدعابة والمرح ِِّ إزالة التوتر. & 12 \\
\hline 1.259 & 3.57 & أنخرط ٍِِ هواية أو اهتمام معين ليساعدني على نسيان الضغوط والاستمتاع بحياتي. & 13 \\
\hline 1.229 & 1.85 & أتناول دواء يساعدني على الاسترخاء أو النوم العميق. & 14 \\
\hline 1.414 & 3.45 & أواظب على نظام غذائي ورياضي صحي. & 15 \\
\hline 1.293 & 2.64 & أكتفي بتجاهل المشكلة وآمل أن تزول. & 16 \\
\hline 1.246 & 3.77 & أصلي أو أتأمل أو أزيد من جرعة الروحانيات. & 17 \\
\hline 1.212 & 3.41 & اعمل على مواجهة أسباب المشكلة والقلق المترتب عليها. & 18 \\
\hline 1.245 & 3.20 & أحاول التركيز على أمور أستطيع السيطرةٌ عليها وأتقبل أمورا لا أستطيع التحكم فيها. & 19 \\
\hline 395. & 3.25 & التعايث مع الضغوط الكلي & 20 \\
\hline
\end{tabular}

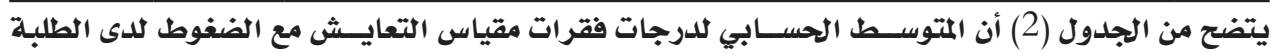

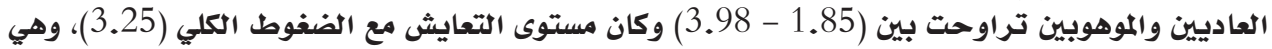

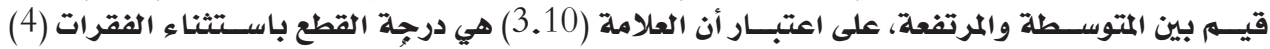

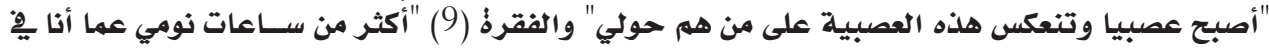

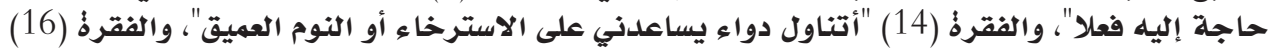

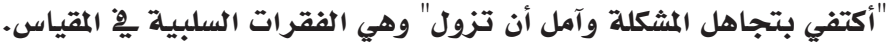




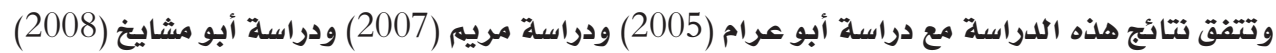

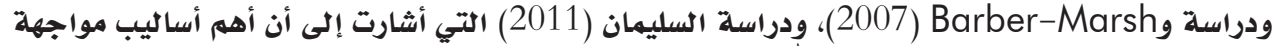

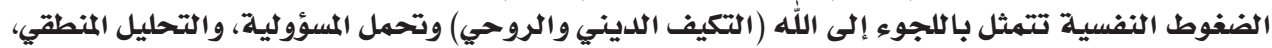

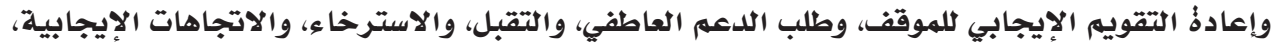

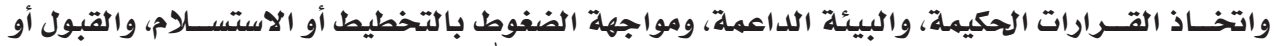

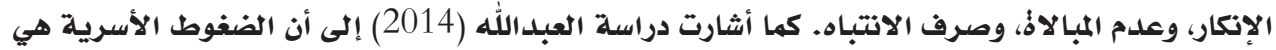

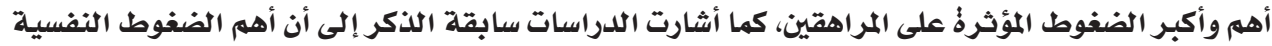

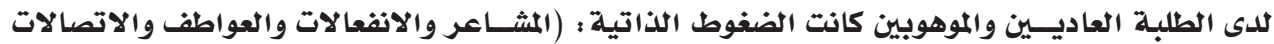

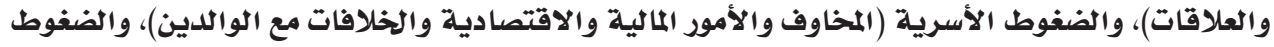

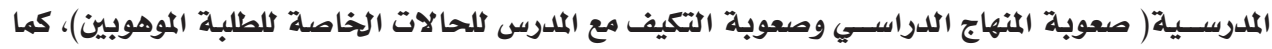

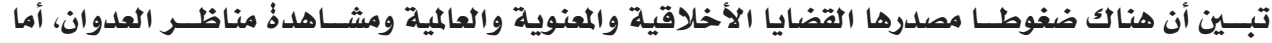

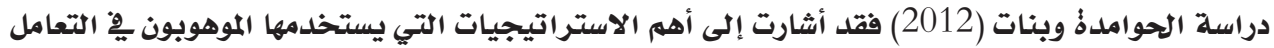

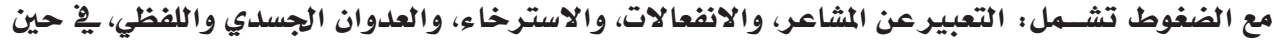

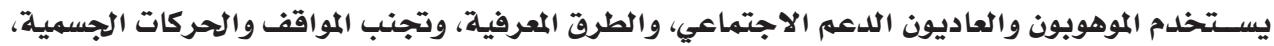
والانعزال، وممارسلة بعض المون العادات.

وقد تم إيجاد مسـتوى التعايث مع الضغوط الكلي لفئات الدراســة (الموهوبين والعاديين)، كما ِِّ الجدول

جلدول (3) : مستوى التعايث مع الضغوط الكلية لفئات الدراسة

\begin{tabular}{|c|c|c|c|c|c|c|}
\hline الإحصائية الدلة & درجات الحرية & "تيمة & الانحراف & المعدل & العدد & الفئة \\
\hline \multirow[t]{2}{*}{.000} & 289 & 4.138 & .339 & 3.11 & 96 & الموهوب \\
\hline & & & .405 & 3.31 & 195 & العادي \\
\hline
\end{tabular}

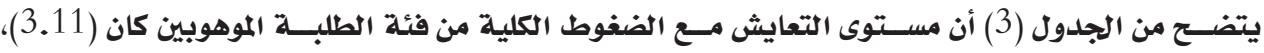

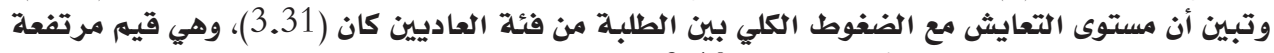

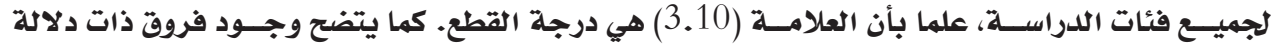

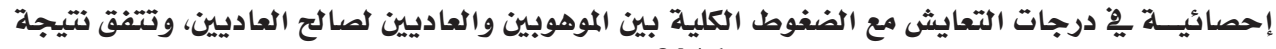

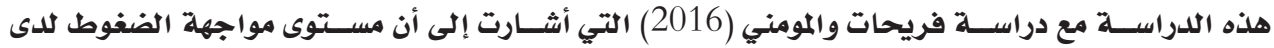

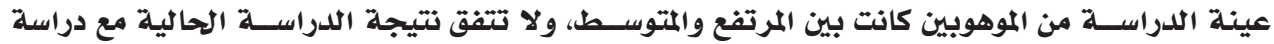
من زماثهم فialle et al. من زملائهم غير الموهوبين.

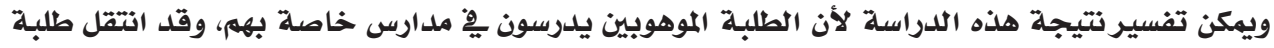

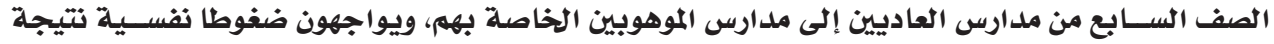

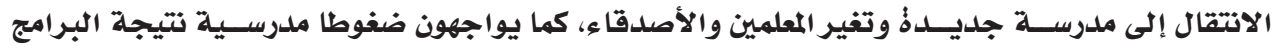

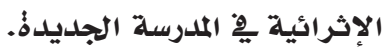

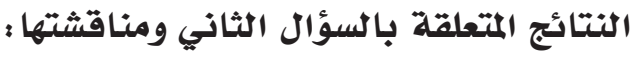

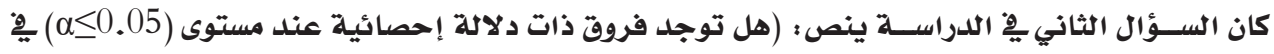

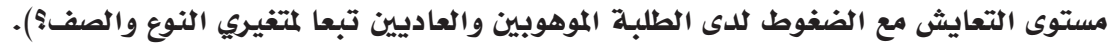
وتم حساب مستوى التعايش مع الضغوط الكلية على متغير النوع الذكور والإناث كما يِّ الجلدول (4). 
فيصل عيسى عبد القادر النواصره موسى سليمان صالح أبو زيتون

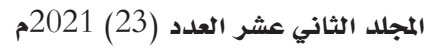

جدول (4) : مستوى الصحة النفسية الكلي على متغير النوع

\begin{tabular}{|c|c|c|c|c|c|c|c|}
\hline الإحصائية & درجات & "تيمة & الانحياري & الحسابي & العدد & النوع & الفئة \\
\hline \multirow[t]{2}{*}{.001} & 193 & 3.502 & .382 & 3.41 & 98 & ذكر & العاديين \\
\hline & & & .406 & 3.21 & 97 & أنثى & \\
\hline \multirow[t]{2}{*}{.038} & 94 & -2.108 & .354 & 3.05 & 52 & ذكر & الموهوبين \\
\hline & & & .306 & 3.19 & 44 & أنثى & \\
\hline \multirow[t]{2}{*}{.090} & 289 & 1.699 & .410 & 3.28 & 150 & ذكر & العينة الكلية \\
\hline & & & .376 & 3.21 & 141 & أنثى & \\
\hline
\end{tabular}

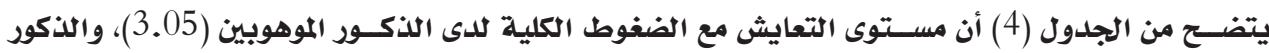

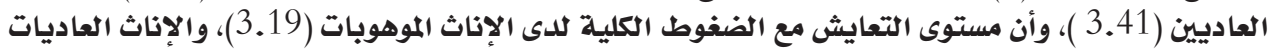

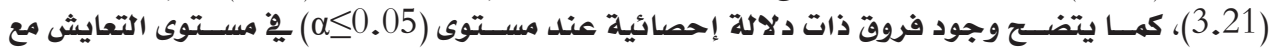

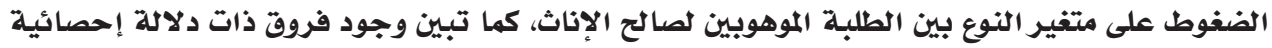

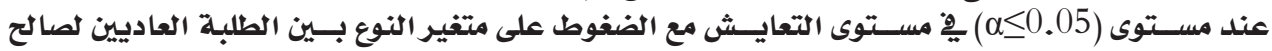

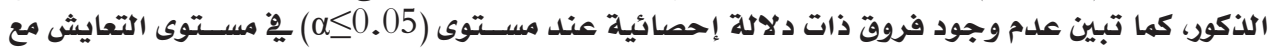

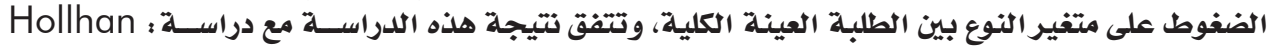

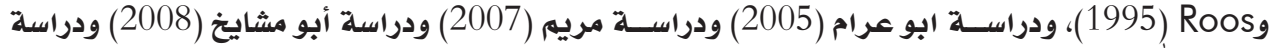

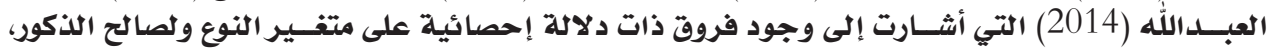

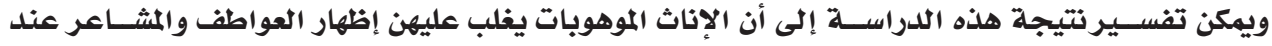

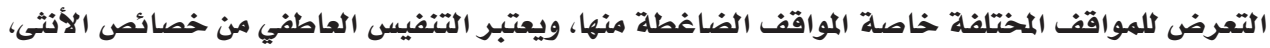

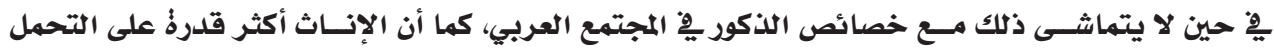

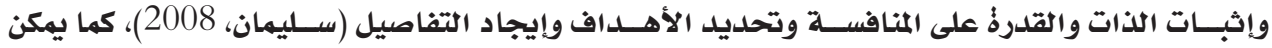

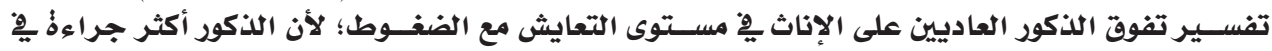

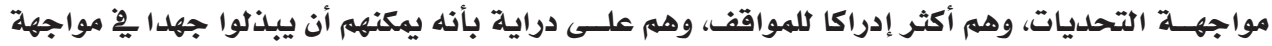

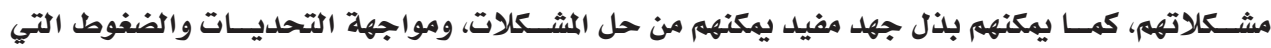

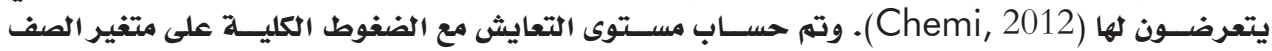

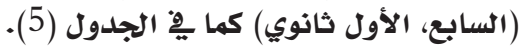

جدول (5) : مستوى التعايش مع الضغوط الكلية على متغير الصف

\begin{tabular}{|c|c|c|c|c|c|c|c|}
\hline الإحصائية & الحرية & "تيمة & الانحراف & الحسابي & العدد & الدراسفي & الفئة \\
\hline \multirow[t]{2}{*}{.878} & 289 & .154 & .414 & 3.25 & 173 & السابع & العاديين \\
\hline & & & .367 & 3.24 & 118 & الأول الثانوي & \\
\hline \multirow[t]{2}{*}{.896} & 193 & -.130 & .410 & 3.31 & 131 & السابع & الموهوبين \\
\hline & & & .398 & 3.32 & 64 & الأول الثانوي & \\
\hline \multirow[t]{2}{*}{.197} & 94 & -1.300 & .373 & 3.06 & 42 & السابع & العينة \\
\hline & & & .308 & 3.15 & 54 & الأول الثانوي & الكلية \\
\hline
\end{tabular}

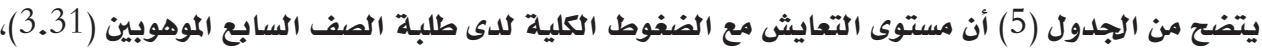

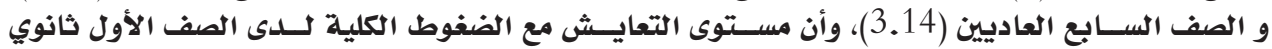

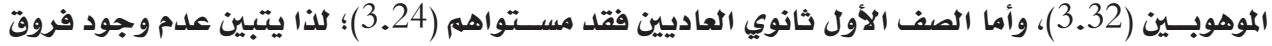

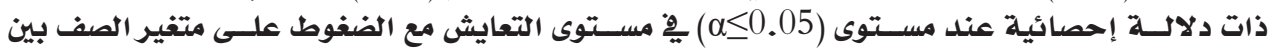

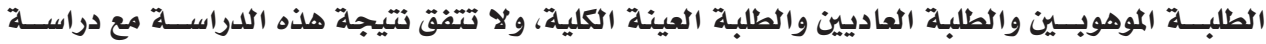


عبدالله (2002) ودراســة العبدالله (2014) اللتين أشـارتا إلى وجود فروق ذات دلاكلة إحصائية لصالح

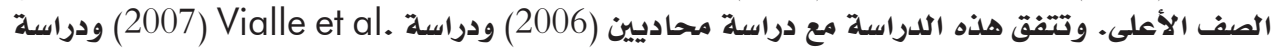

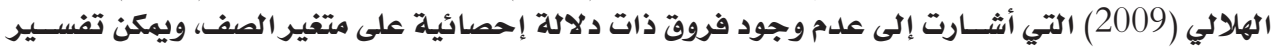

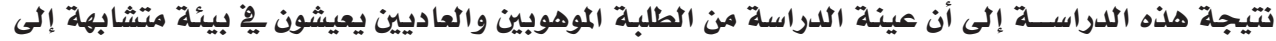

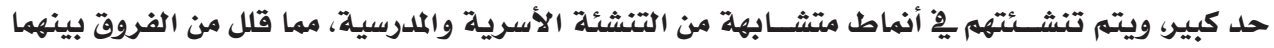

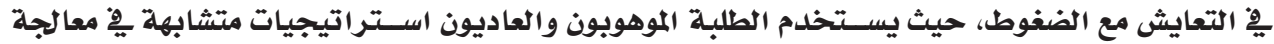

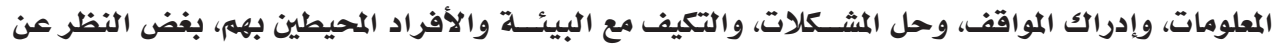

العهر - المبر

النتائج المتعلقة بالسؤال الثالث ومناقشتها :

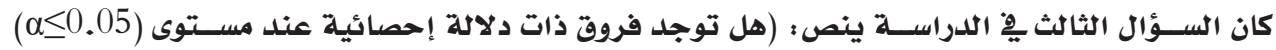

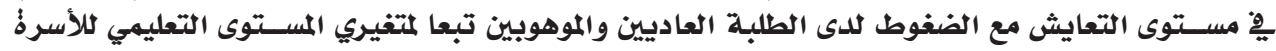

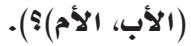

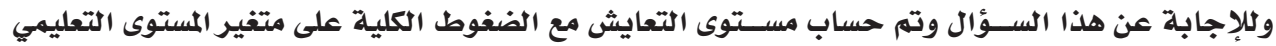

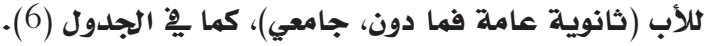
جدول (6): مستوى التعايث مع الضغوط الكلية على متغير المستوى التعليمي للاب

\begin{tabular}{|c|c|c|c|c|c|c|c|}
\hline الإحصائيـة الدلة & الحرية & "قيمة & الانحراف & المتوسطابي & العدد & المستوى التعليهي ذلأب & الفئة \\
\hline \multirow[t]{2}{*}{.780} & 94 & .280 & .348 & 3.13 & 35 & ثانوية عامه فما دون & العاديين \\
\hline & & & .337 & 3.11 & 61 & 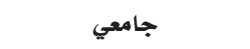 & \\
\hline \multirow[t]{2}{*}{.937} & 193 & .080 & .420 & 3.31 & 138 & ثانوية عامه فما دون & الموهوبين \\
\hline & & & .372 & 3.31 & 57 & جامعي & \\
\hline \multirow[t]{2}{*}{.128} & 289 & 1.525 & .412 & 3.28 & 173 & ثانوية عامه فما دون & 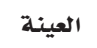 \\
\hline & & & .367 & 3.20 & 118 & جامعي & الكلية \\
\hline
\end{tabular}

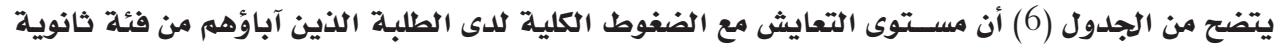

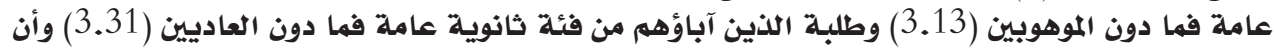

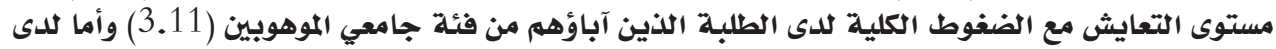

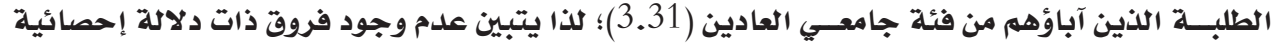

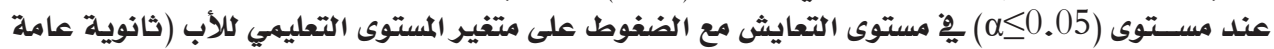

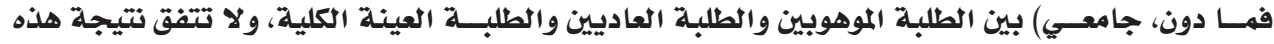

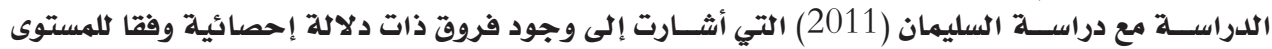
التعليمي لكلأب.

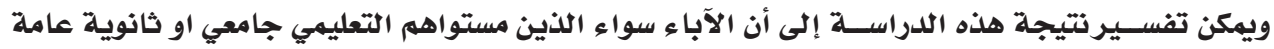

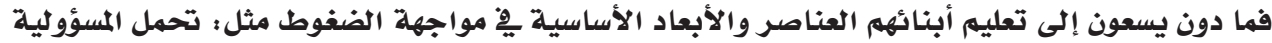

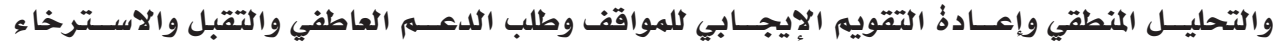

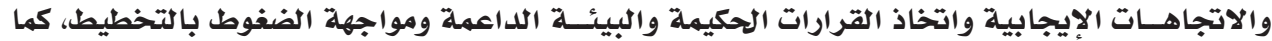

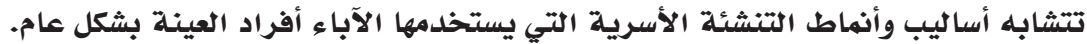

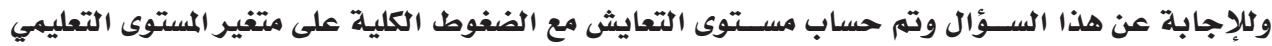

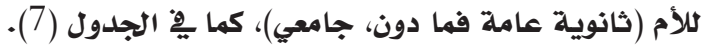


فيصل عيسى عبد القادر النواصره موسى سليمان صالح أبو زيتون

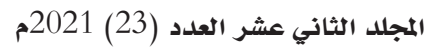

جلدول (7): مستوى التعايث مع الضغوط الكلية على متغير المستوى التعليمي للام

\begin{tabular}{|c|c|c|c|c|c|c|c|}
\hline الإحصائية الدلاية & درجات & "تيمة & الانححراف & المتوسطابي & العدد & المستوى التعليهي كلأم & الفئة \\
\hline \multirow[t]{2}{*}{.899} & 193 & .128 & .420 & 3.32 & 109 & ثانوية عامه فها دون & العاديين \\
\hline & & & .388 & 3.31 & 86 & 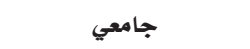 & \\
\hline \multirow[t]{2}{*}{.580} & 94 & .556 & .354 & 3.15 & 19 & ثانوية عامه فما دون & الموهوبين \\
\hline & & & .337 & 3.10 & 77 & جامعي & \\
\hline \multirow[t]{2}{*}{.088} & 289 & 1.711 & .414 & 3.29 & 128 & ثانوية عامه فما دون & 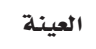 \\
\hline & & & .378 & 3.21 & 163 & جامعي & الكلية \\
\hline
\end{tabular}

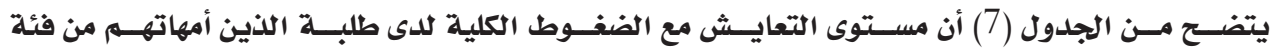

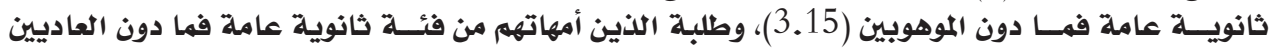

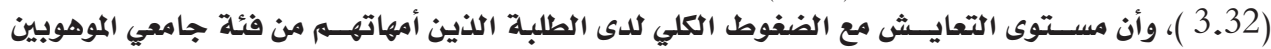

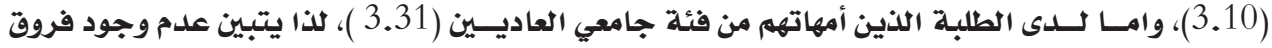

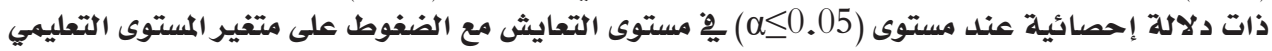

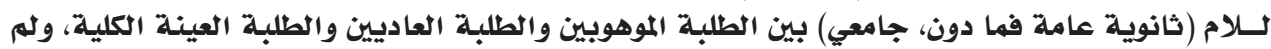

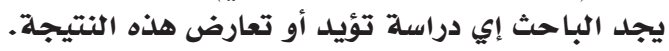

ويمكن تفسـير نتيجهة هذه الدراســة إلى أن الأمهات ســـواء الذين مســتواهم التعليهي جامعي او ثانويـة

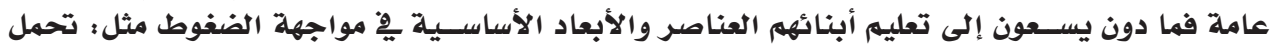

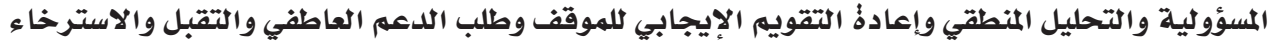

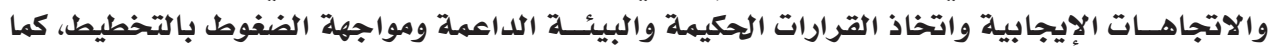
تتشابه أساليب وأنماط التنشئة الأسريـة التي تستخلهما الأمهات أفراد العينة بشكل عام.

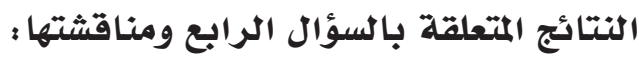

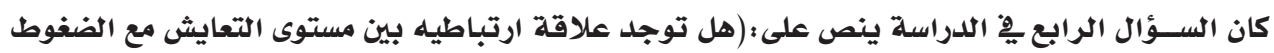
والتحصيل الدراسي بين الطلبة الموهوبين والعاديين؟).

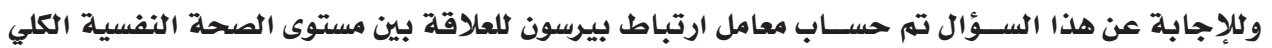

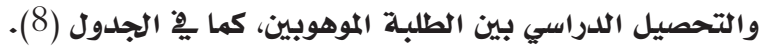
جدول (8) : معامل ارتباط بيرسون للعلاقة بين مستوى التعايث مع الضغوط الكلية والتحصيل الدراسي للدى الطلبة الموهوبين والعاديين والعينة الكلية التعايث الفوط الفية

\begin{tabular}{|c|c|c|}
\hline معدل الطالب & الإحصائي المستخلدم & الفئة \\
\hline .174 & معامل الارتباط ر & الموهوبين \\
\hline .089 & الدلالة الإحصائية & \\
\hline $\left..180^{*}\right)$ & معامل الارتباط ر & العاديين \\
\hline .012 & الدلالة الإحصائية & \\
\hline $\left..117^{*}\right)$ & معامل الارتباط ر & الكلي \\
\hline .046 & الدلادلة الإحصائية & \\
\hline
\end{tabular}

دالة إحصائيا عند مستوى الدلاية (0.05).

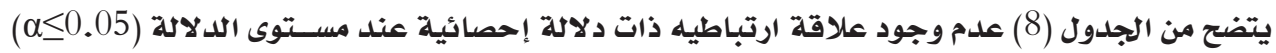
بين مستوى التعايث مع الضغوط الكلية والتحصيل الدراسي للموهوبين، كما تبين وجود علاقوة ارتئ ارتباطيه 
ذات دلالة إحصائية عند مســتوى الدلالة (ب00.05) بين مستوى التعايث مع الضغوط الكلي والتحصيل الدراسي بين الطلبة العاديين وعلى العينة العيلة الكلية.

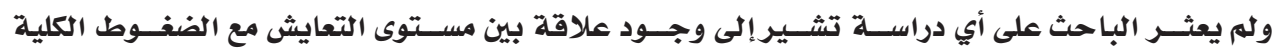

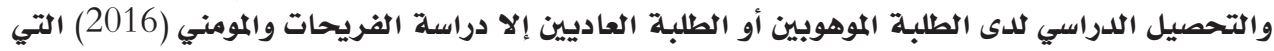

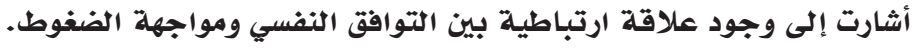

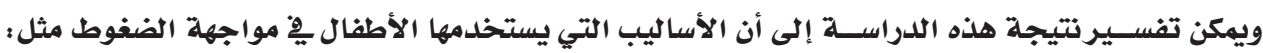

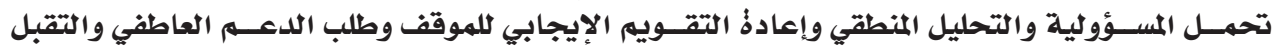

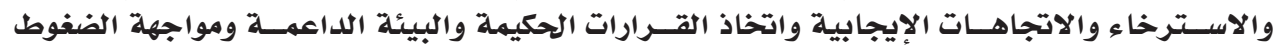

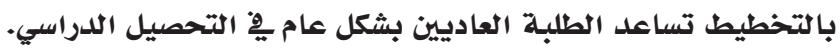

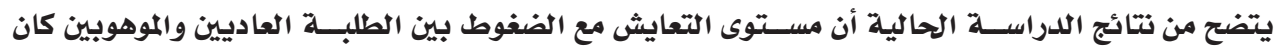

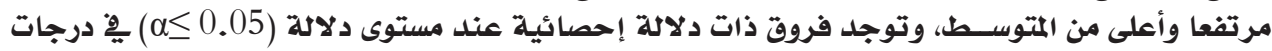

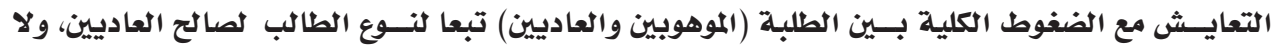

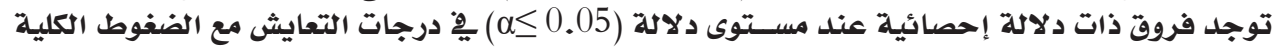

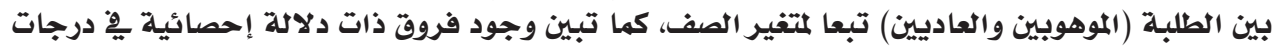

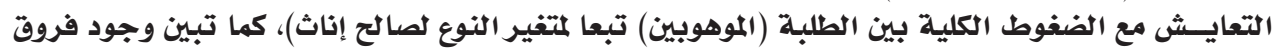

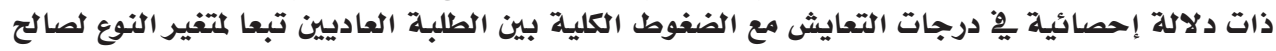

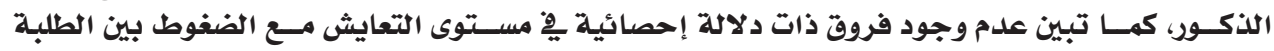

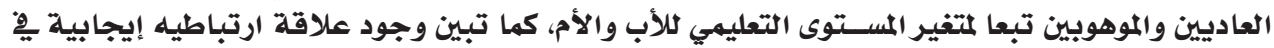

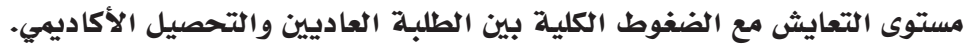

التوصيات:

ويفْ ضوء نتائج البحث يوصي البـاحث بــالآتي:

ه ضرورةٌ بنـاء بر امج للتعايث مع الضغوط وأسـاليب مواجهة المشــكلات النفسـية للطلبة العاديـين

والموهوبين.

ه ضرورةٌ مراعاذٌ الفروق الفردية بين الطلبة لاختلاف أســاليب التنشـــة الأسرية وتأثير العوامل

الديهوغرافية.

المقترحات:

وبِ ضوء نتائج البحث يقترح الباحث الآتي:

ه ضرورةٌ إجراء المزيل من الدراسات حول التعايث مع الضغوط لدى فئات أخرى من ذوي الاحتياجات

الاخاصة.

ه إجراء دراسة حول علاقة التعايش مع الضغوط بأنماط التنشئة الأسرية ومفهوم الذات.

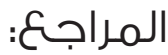

أبو عرام، أمل علاء الدين حســن (2005). أسـاليب مواجهة الضغوط وعلاقتها ببعض سهات الشـخصية

(أطروحة دكتوراه). جامعة عين شمس، (المس، مصر.

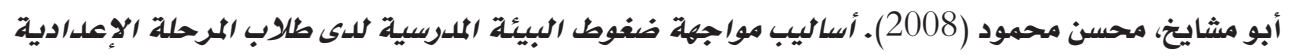

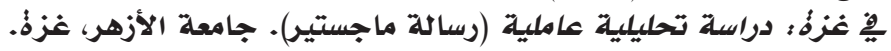


فيصل عيسى عبد القادر النواصره موسى سليمان صالح أبو زيتون

المجلد الثاني عشر العدد (23) 2021م سئون

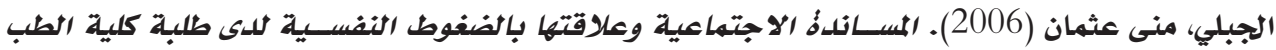

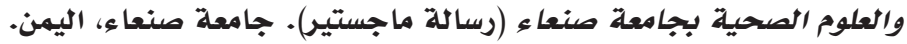

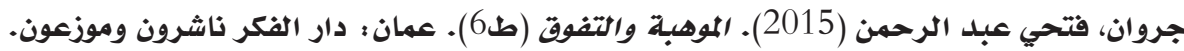

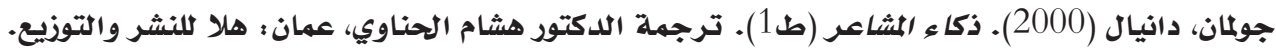

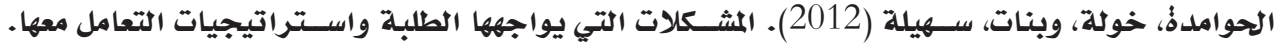

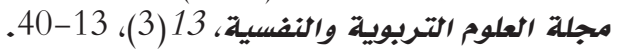

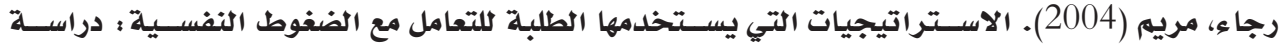

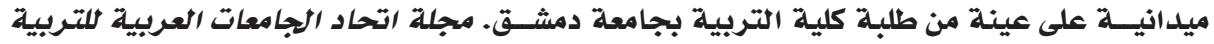

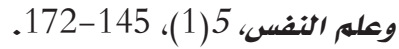

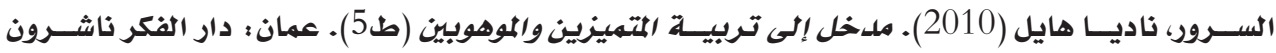
وموزعون.

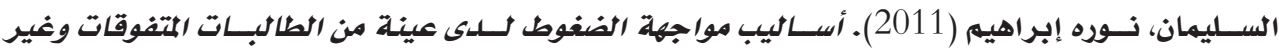

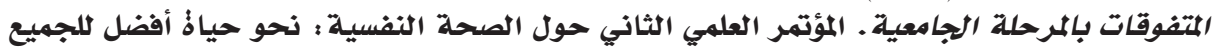

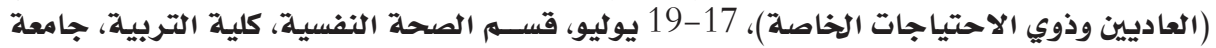
بنها، مصر. شتات، ابتسام محمود (2008). العلاقة بين إدارةٌ الوقت وأساليب مواجهة الضغوط ودافعية الإنجاز للدى

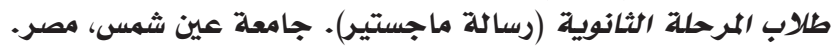

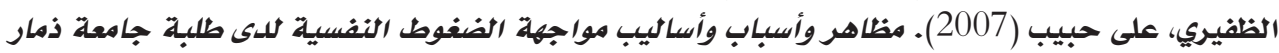
وعلاقتها ببعض حبيب المتغيرات (رسالة ماجستير). جامعة ذائ ذمار، اليمن.

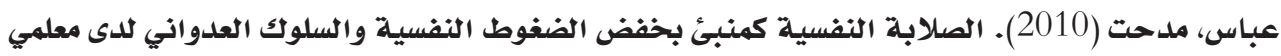

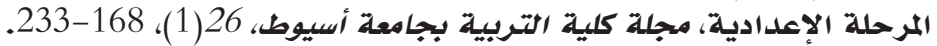

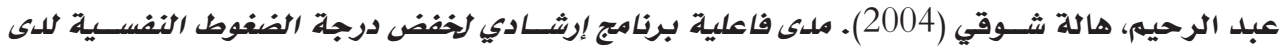
الطالبات المستجلدات بالملدن الجامعية بجامعة حلوان (رسان (رسالة ماجستير). جامعة عين شمس، مصر.

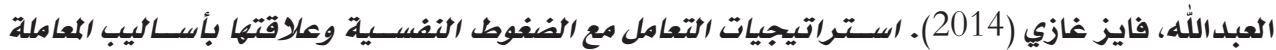

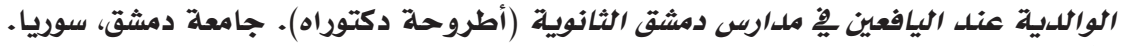

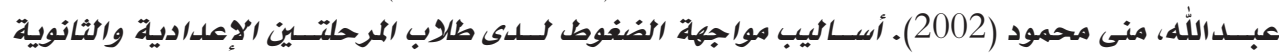

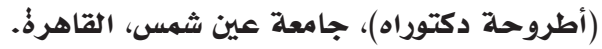

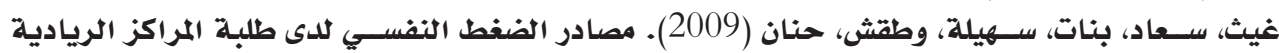

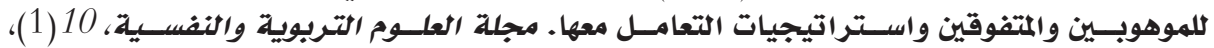
.268-246

الفريحــات، عمار عبــدالله، والمومني، فخري فلاح (2016). التوافق النفســي وعلاقتـــه بمهارات مواجهة

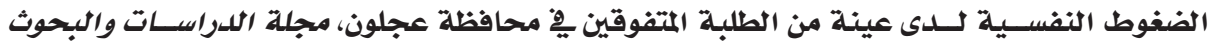

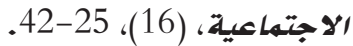

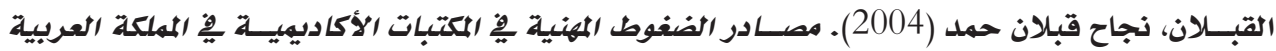

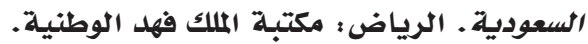

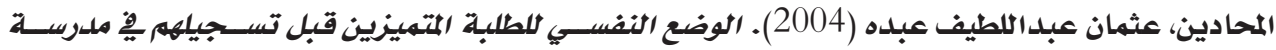
المتهيزين وبعلده: دراسة مقارنة (رسالة ماجستير)، الجامعة الهاشمية، الهابية، الأردن.

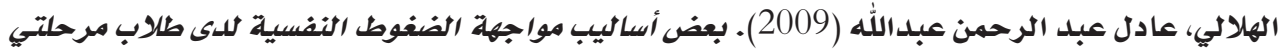
التعليه المتوسط والثانوي بهلدينة مكة المكرمة (رسالة ماجستير). جامعة أم القرى، مكة المكرمة. 
Barber-Marsh, K. A. (2007). An exploration of giffed and highly able adolescents' experiences with stress and coping (Master thesis). Brock University, St. Catharines, Ontario.

Chan, D. W. (2004). Social coping and psychological distress among Chinese gifted students in Hong Kong. Gifted Child Quarterly, 48(1), 30-41.

Chemi, T. (2012). The future of artistic creativity: Models of integration in school curriculum. In International Conference about the Future of Education (pp. 58-64). Florence, Italy: Simonelli Editore.

Colangelo, N., \& Davis, G. A. (1997). Handbook of gifted education. Boston, $M A:$ Allyn and Bacon.

Cross, T. L., \& Swiatek, M. A. (2009). Social coping among academically giffed adolescents in a residential setting: A longitudinal study. Gifted Child Quarterly, 53(1), 25-33.

Davis, M., Eshelman, E. R., \& McKay, M. (2000). Coping Styles Questionnaire. Adapted by Jim Boyers, (1999), Kaiser-Permanente Medical Center and Health Styles. Oakland, CA: New Harbinger Productions.

Holahan, C. J., Moos, R. H., Holahan, C. K., \& Brennan, P. L. (1995). Social support, coping, and depressive symptoms in a late-middle-aged sample of patients reporting cardiac illness. Health Psychology, 14(2), 152.

Mendaglio, S. (2005). Counseling gifted persons: Taking giffedness into account. Giffed Education International, 19(3), 204-212.

Richards, K., Campenni, C., \& Muse-Burke, J. (2010). Self-care and well-being in mental health professionals: The mediating effects of self-awareness and mindfulness. Journal of Mental Health Counseling, 32(3), 247-264.

Seaward, B. L. (1999). Managing stress: Principles and strategies for health and wellbeing. Burlington, MA: Jones \& Bartlett Learning.

Vialle, W., Heaven, P. C., \& Ciarrochi, J. (2007). On being gifted, but sad and misunderstood: Social, emotional, and academic outcomes of gifted students in the Wollongong Youth Study. Educational Research and Evaluation, 13(6), 569-586.

\section{Arabic References in Roman Scripts:}

Abbas, Medhat (2010). Alsalabat alnafsiat kamanbi bikhafd aldughut alnafsiat walsuluk aleudwanii ladaa muealimi almarhalat al'iiedadiati. Majalat Kuliyat Altarbiat Bijamieat Asyut, 26(1), 168-233.

Abdel Rahim, Hala Shawky (2004). Madaa faeiliat barnamaj 'iirshadiun likhafd darajat aldughut alnafsiat ladaa altaalibat almustajadaat bialmudun aljamieiat bi Jamieat Hulwan (Risalat majistir). Jamieat Eayn Shams, Misr. 
فيصل عيسى عبد القادر النواصره موسى سليمان صالح أبو زيتون

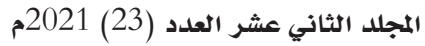

Abdullah, Mona Mahmoud (2002). Asalib muajahat aldughut ladaa tulaab almarhalatayn al'iiedadiat walthaanawia (Utaruhat dukturah). Jamieat Eayn Shams, Alqahira.

Abu Aram, Amal Aladdin Hassan (2005). Asalib muajahat aldughut waealaqatiha bibaed simat alshakhsia (Utaruhat dukturah). Jamieat Eayn Shams, Misr.

Abu Mashaikh, Mohsen Mahmoud (2008). Asalib muajahat dughut albiyat almadrasiat ladaa tulaab almarhalat al'iiedadiat fi Ghaza: Dirasat tahliliat eamilia (Risalat majistir). Jamieat Al'azhara, Ghaza.

Al-Abdullah, Fayez Ghazi (2014). Astiratijiaat altaeamul mae aldughut alnafsiat waealaqatiha bi'asalib almueamalat alwalidiat eind alyafiein fi madaris Dimashq althaanawia (Utaruhat dukturah). Jamieat Dimashqa, Suria.

Al-Dhafiri, Ali Habib (2007). Mazahir wa'asbab wa'asalib muajahat aldughut alnafsiat ladaa talbat Jamieat Dhimar waealaqatiha bibaed almutaghayirat (Risalat majistir). Jamieat Dhimari, Alyaman.

Al-Fraihat, Ammar Abdullah, and Al-Momani, Fakhri Falah (2016). Altawafuq alnafsiu waealaqatuh bimaharat muajahat aldughut alnafsiat ladaa eayinat min altalabat almutafawiqin fi muhafazat Eajlun. Majalat Aldirasat Walbuhuth Alaijtimaeiati, (16), 25-42.

Al-Gabali, Mona Othman (2006). Almusanadat alaijtimaeiat waealaqatuha bialdughut alnafsiat ladaa talbat kuliyat altibi waleulum alsihiyat bi Jamieat Sana'a (Risalat majistir). Jamieat Sana'a, Alyaman.

Al-Hawamdeh, Khawla, wa Banat, Suhaila (2012). Almushkilat alati yuajihuha altalabat wastiratijiaat altaeamul mieaha. Majalat Aleulum Altarbawiat Walnafsiati, 13(3), 13-40.

Al-Hilali, Adel Abdul-Rahman Abdullah (2009). Baed 'asalib muajahat aldughut alnafsiat ladaa tulaab marhalatay altaelim almutawasit walthaanawiu bimadinat Makkat Almukarama (Risalat majistir). Jamieat Umm Alquraa, Makkat Almukaramati.

Al-Mahadin, Othman Abdul Latif Abdo (2004). Alwade alnafsiu liltalabat almutamayizin qabl tasilihim fi madrasat almutamayizayn wabaedahu: dirasat muqarana (Risalat majistir). Aljamieat Alhashimiati, Al'urdunn.

Al-Qablan, Najah Qabalan Hamad (2004). Masadir aldughut almihniat fi almaktabat al'akadimiat fi Almamlakat Alearabiat Alsaeudia. Alriyad: Maktabat Almalik Fahd Alwataniati.

Al-Sulaiman, Norah Ibrahim (2011). Asalib muajahat aldughut ladaa eayinat min altaalibat almutafawiqat waghayr almutafawiqat bialmarhalat aljamieiati. Almutamar Aleilmiu Althaani hawl Alsihat Alnafsiati: Nahw Hayaat Afdal Liljamie (Aleadiiyn Wadhawi Alaihtiajat Alkhasati), 17-19 Yuliu, Qism Alsihat Alnafsiati, Kuliyat Altarbiati, Jamieat Binha, Misr. 
Al-Surour, Nadia Hayil (2010). Madkhal 'iilaa tarbiat almutamayizayn walmawhubayn (Taba'a 5). Amman: Dar Alfikr Nashirun Wamuazieuna.

Ghaith, Souad, Girls, Suhaila, wa Taqsh, Hanan (2009). Masadir aldaght alnafsii ladaa talabat almarakiz alriyadiat lilmawhubin walmutafawiqin wastiratijiaat altaeamul mieaha. Majalat Aleulum Altarbawiat Walnafsiati, $10(1), 246-268$.

Goleman, Daniel (2000). Thaka' almashaeir (Taba'a 1). Tarjamat Alduktur Hisham Alhanawi, Amman: Hala Lilnashr Waltawziei.

Jarwan, Fathi Abdel Rahman (2015). Almawhibat waltafawuq (Taba'a 6). Amman: Dar Alfikr Nashirun Wamuazieuna.

Raja, Maryam (2004). Alastiratiiiaat alati yastakhdimuha altalabat liltaeamul mae aldughut alnafsiati: Dirasat maydaniat ealaa eayinat min talbat kuliyat altarbiat bi Jamieat Dimashqa. Majalat Aitihad Aljamieat Alearabiat Liltarbiat Waeilm Alnafsi, 5(1), 145-172.

Shatat, Ibtisam Mahmoud (2008). Alealaqat bayn 'iidarat alwaqt wa'asalib muajahat aldughut wadafieiat al'iinjaz ladaa tulaab almarhalat althaanawia (Risalat majistir). Jamieat Eayn Shams, Misr. 